\title{
OS MERCADOS MUNDIAIS DE AÇÚCAR E A EVOLUÇÃO DA AGROINDÚSTRIA CANAVIEIRA DO BRASIL ENTRE 1930 E 1980: DO AÇÚCAR AO ÁLCOOL PARA O MERCADO INTERNO
}

\author{
Pedro Ramos ${ }^{\S}$
}

\begin{abstract}
RESUMO
A produção e o consumo de açúcar são bastante antigos. Também são antigas as práticas dos países desenvolvidos destinadas a apoiar e proteger seus mercados deste bem, o que se ampliou após a crise de 1929, passando a existir tanto o mercado livre mundial como os mercados preferenciais. Este trabalho analisa estas relações com a evolução da agroindústria canavieira do Brasil, mostrando que as exportações brasileiras alcançaram um novo patamar apenas depois da entrada do nosso açúcar no mercado preferencial norte-americano, já que, até então, nossa produção de açúcar esteve voltada ao consumo interno e a ela esteve associado o mercado de álcool carburante.
\end{abstract}

Palavras-chave: Brasil, mercados, açúcar, álcool, acordos.

\begin{abstract}
The production and the consumption of sugar are very old. The practices of the developed countries destined to support and to protect yours markets of this product are also old, what was enlarged after the crisis of 1929, starting to exist as much the world free market as the preferential markets. This paper analyzes the relationships of this with the evolution of the sugar's agroindustry of Brazil, showing that the Brazilian exports just reached a new level after the entrance of our sugar in the North American preferential market, since until then our production of sugar was destined to the internal consumption and the market of alcohol fuel it was associated.
\end{abstract}

Key words: Brazil, markets, sugar, alcohol, agreements.

JEL Classification: N80, Q13.

$\S \quad$ Professor/Pesquisador do IE/Unicamp. Doutor pela EAESP/FGV. E-mail: peramos@eco.unicamp.br. Endereço para contato: Instituto de Economia - UNICAMP - Caixa Postal n. 6135 - Cidade Universitária Prof. Zeferino Vaz - CEP 13083 -970 - Campinas, SP.

Recebido em abril de 2007. Aceito para publicação em maio de 2007. 


\section{INTRODUÇÃo}

Este trabalho pretende contribuir para o melhor conhecimento de um período relativamente recente da história brasileira, tendo como objeto de análise o caso do mercado de açúcar. É feita uma breve síntese do período anterior à crise de 1929, na qual é destacada a relação da produção brasileira de açúcar com o comércio mundial, tendo em conta produtores e produto concorrentes, evidenciando-se a perda do mercado externo pelo Brasil.

A parte principal do trabalho trata do período 1930 a 1965, no qual o açúcar passou a ser um produto industrial de grande importância no mercado interno, pois é fruto de um complexo produtivo, cuja expansão fez parte do próprio processo de industrialização da economia brasileira. Contudo, dadas as suas dimensões e as diferenças regionais, tal complexo, sob intervenção estatal de âmbito federal desde 1931, apresentava um excedente de produção, cujo destino foi o mercado externo, no qual era vendido a preços gravosos. Esta situação relacionou-se com a existência dos denominados "mercados preferenciais" e com os fracassos dos acordos internacionais que buscavam a estabilização dos preços. Isto perdurou até o início dos anos 1960, quando a revolução cubana tornou possível a entrada do açúcar brasileiro no mercado norte-americano e a exportação passou a ser objeto de maior preocupação da intervenção estatal. Entre 1966 e 1980, depois do período de altos preços do açúcar obtidos nas exportações, a criação do Proálcool em 1975 permitiu uma grande ampliação do mercado interno de álcool carburante, que já existia desde a década de 1930 .

\section{ANTECEDENTES HISTÓRICOS: A CONCORRÊNCIA DO AÇÚCAR DE BETERRABA E A PERDA DO MERCADO EXTERNO PELO AÇÚCAR BRASILEIRO}

\subsection{De produto agrícola a produto industrial e práticas antigas}

O açúcar obtido a partir da cana é um produto de consumo humano bastante antigo, tendo sido inicialmente utilizado como remédio e produzido para autoconsumo. (ver Lippmann, 1940, p. 201). A leitura desta excelente obra evidencia como seu mercado (produção e consumo) expandiu-se muitíssimo no período das grandes descobertas, tendo se tornado uma das principais mercadorias da era mercantilista, envolvendo todas as metrópoles européias, com sua produção concentrada em áreas tropicais e sendo responsável pela busca e/ou ocupação de novas terras, que originaram invasões e guerras. Até o início do século XIX, o açúcar de cana podia ser visto como um bem tipicamente agrícola e reinava absoluto no comércio mundial. Segundo Mont'Alegre (1976/1977, p. 175-176), a perda de competitividade do açúcar das Índias Ocidentais Britânicas, a partir da abolição ocorrida em 1833, está vinculada à luta pela extinção da escravidão empreendida pela nação hegemônica de então. Contudo, o fato é que o mercado mundial do açúcar estava em grande transformação.

Primeiro, porque sua produção passou a ser submetida às invenções e desenvolvimentos técnicos que configuraram a Primeira Revolução Industrial, tornando-o um produto tipicamente industrial, com as metrópoles realizando investimentos para modernizar as produções de suas colônias. Os casos mais evidentes disso são o de Cuba e o de Java. Como se sabe, Cuba, principalmente depois da independência, passou a receber investimentos estrangeiros, especialmente norte- 
americanos, que em pouco tempo tornaram este país o maior produtor mundial de açúcar. Cabe destacar a concentração ocorrida na indústria açucareira cubana: se em 1904 a produção média das "centrales" era de 6.047 t, em 1930 tal média chegou a 29.114 t. (López, 1982, p. 94). Em Java, destacou-se o investimento holandês no melhoramento genético da cana. Portanto, a agroindústria açucareira também esteve submetida ao movimento internacional de capitais que ocorreu entre o final do século XIX e o início do século XX.

Segundo, porque surgiu a indústria de açúcar de beterraba. Embora a primeira experiência fabril tenha sido feita na Prússia em 1796, foi na França que tal indústria desenvolveu-se mais rapidamente, em função do contrabloqueio inglês imposto a Napoleão, que, vendo interrompido o fornecimento colonial, implementou uma política de apoio que tornou aquele país o primeiro grande produtor europeu. Após a guerra, embora tenha sido combatida em face dos interesses coloniais e fiscais, os quais chegaram a pedir sua extinção na França, e duvidando-se que seria um produto semelhante ao de cana na Inglaterra, o fato é que a produção e o consumo de açúcar de beterraba consolidaram-se, e isso reforçou a face industrial deste bem, que, assim, passou a ser obtido também nas áreas de clima temperado. Estabeleceu-se então uma concorrência entre as produções originadas ao sul e ao norte do Equador, já que são poucos os países que produziam, no período aqui estudado, tanto açúcar de cana como de beterraba. A constituição dos complexos açucareiros no interior dos países desenvolvidos associou-se à disponibilidade de terras para o cultivo da matéria-prima (ex da França e da Alemanha); na ausência de tal disponibilidade (ex do Japão), ocorreu um predomínio do refino, com alguns países tornando-se grandes importadores de açúcar demerara (raw sugar).

Não obstante, ainda hoje há uma parte da produção de açúcar que tem um processamento rudimentar, que o faz parecer um produto agrícola. Pode-se tomar como exemplos disto o gur na Índia e a rapadura no Brasil. A distinção entre um açúcar tipicamente industrial e um "agrícola" tem sido feita com base na existência ou não do processo de centrifugação nas unidades produtoras.

Com a generalização das políticas protecionistas e de auxílio estatal, a produção de açúcar de beterraba passou, de uma participação de $14 \%$ em 1852/1853 para a média de $63 \%$ do total de açúcar produzido no mundo na virada do século. (conf. dados de Cabral, 1936, p. 242). Não tardou para que a oferta mundial de açúcar passasse a exceder o consumo.

A literatura aponta que a primeira tentativa de acordo sobre o mercado de açúcar de beterraba europeu ocorreu em 1864, com a participação da Bélgica, França, Países Baixos e Reino Unido. Tendo como objetivo pôr fim aos subsídios à exportação entre eles:

"A medida não alcançou o sucesso esperado, resultando, antes, no agravamento da questão, pois os países não participantes, em geral subsidiados pelos respectivos Governos, gozavam de isenção de impostos fiscais e conseguiam colocar o açúcar de sua produção nos países participantes do Acordo, por preços mais baixos do que o produzido neles próprios." (IAA, 1972, p. 170).

Outras tentativas de acordo ocorreram em 1875, 1877 e 1888. Contudo, logrou-se um novo acordo apenas em 1902 (conhecido como “Convenção de Bruxelas”), o qual incluiu, além daqueles países, a Alemanha, Áustria/Hungria, Itália, Espanha e Noruega. A estes países juntaram-se, em 1907, Luxemburgo, Suíça e Peru e, em 1908, a Rússia. Novamente, buscou-se a supressão dos estímulos à produção e à exportação de açúcar, seja de beterraba, seja de cana, mas com a introdução 
de um imposto compensatório sobre o açúcar vindo de países que concediam apoio àquelas. Na avaliação de Mont'Alegre (1976/1977, p. 177), a entrada do Peru (único país exportador de açúcar de cana) neste acordo deveu-se à intenção de livrar seu produto destinado à Europa daquele imposto.

Uma outra medida prevista na convenção parece ter sido a razão principal de seu sucesso até o advento da Primeira Grande Guerra, quando cessaram seus efeitos: foi o esforço para a popularização do consumo de açúcar, o qual, se em 15 anos (entre 1888 e 1902) havia se elevado em 4 milhões de toneladas, em 12 anos (entre 1902 e 1914), elevou-se em 8 milhões. (Mont'Alegre, 1976/1977, p. 177).

Uma nova crise era iminente quando a guerra iniciou-se. Embora esta a tenha evitado, o fato é que o problema de abastecimento que ela causou contribuiu para ampliar e enraizar o comportamento de busca de autarcia no mercado de açúcar no pós-guerra. Isto fez com que a média produzida de 4.935 mil t de açúcar de beterraba no mundo em 1920/1921, 1921/1922, 1922/1923 tenha chegado a 8.332 mil t em 1925/1926, 1926/1927, 1927/1928, com a produção total (de cana e de beterraba), nas médias dos mesmos períodos, tendo se elevado de 17.525 para $24.910 \mathrm{t}$.

Contribuiu para isso o que ocorria no outro lado do Atlântico, onde cabe destacar o caso dos EUA. Em 1876, este país estabeleceu um acordo de reciprocidade comercial com o Reino do Havaí, produtor de açúcar de cana, tendo sido a primeira área fora do continente a receber proteção tarifária. Em 1902, ela foi estendida à Cuba, também sob um tratado de reciprocidade, com $20 \%$ de preferência na tarifa básica. A importância desta trajetória fica marcada pelo seguinte: se na média de 1897-1901, o mercado dos EUA foi abastecido com 53,5\% de açúcar "estrangeiro", ou seja, não proveniente da área continental, das áreas insulares (Havaí, Porto Rico, Filipinas e Ilhas Virgens) e de Cuba; em 1932, tal porcentual foi de apenas 0,4. (ver Dalton, 1937, p. 12 e 21).

Pode-se afirmar que as políticas açucareiras estão entre as mais antigas políticas setoriais implementadas pelas nações desenvolvidas, dada a importância do açúcar para o consumo humano e como produto de um complexo de atividades urbanas e rurais.

\subsection{O caso brasileiro: do mercado externo ao mercado interno em formação}

No Brasil, tentou-se implementar, tardiamente, uma política de modernização da produção açucareira, com a "importação" da idéia de constituição dos "engenhos centrais", que se baseava no princípio da divisão do trabalho e na qual caberia ao capital estrangeiro dedicar-se à atividade industrial e aos proprietários fundiários brasileiros cuidar do cultivo da cana. Tal iniciativa fracassou devido à estrutura de poder então vigente nos principais Estados produtores de açúcar no Brasil (Pernambuco, São Paulo e Rio de Janeiro), tendo ocorrido uma modernização que se concentrou no processamento fabril, mas de maneira parcial. Assim, pode-se afirmar que o advento das novas fábricas, que passaram a ser chamadas de "usinas", significou quase que tão somente uma ampliação quantitativa da capacidade de produção dos antigos engenhos, cabendo destacar a introdução da centrifugação, ou seja, a produção de açúcar branco. Este processo está tratado detalhadamente em Ramos (1999, cap. 1).

Tal fracasso fez com que a produção brasileira perdesse competitividade perante suas principais concorrentes mundiais (as de Cuba e de Java), o que, aliado à concorrência da produção subsidiada/protegida do açúcar de beterraba, explicam a perda do mercado externo pelo açúcar brasileiro ao longo do século XIX. Essa perda foi responsável pelo fato de que, em 1830, o Brasil contribuía 
com $15 \%$ do total da produção mundial de açúcar de cana; Cuba com $13 \%$ e a Ásia com 2,8\%; em 1880, as contribuições foram de $11,2 \%, 28 \%$ e $21,5 \%$; já a participação do açúcar no valor total das exportações brasileiras caiu da média de 32,2\% em 1821/1830 para 1,4\% em 1921/1930. (dados retirados de IAA, 1972, p. 163 e de Brasil Açucareiro, mar. 1959, p. 34).

Foi fundamental no redirecionamento do açúcar para o mercado interno a imigração, principalmente para São Paulo, cuja economia estava em franca expansão devido ao dinamismo gerado pelo complexo cafeeiro, o qual necessitava de braços para o trabalho nas terras virgens de que dispunha a província/Estado. Ressalta a importância disto o fato de que, entre 1822 e 1932, entraram no País 4.582.552 estrangeiros, a esmagadora maioria após 1889 e com metade deles fixando-se em São Paulo. (Albuquerque e Nicol, 1987, p. 197).

Estas observações foram feitas porque ainda hoje é comum encontrar estudiosos que tem o açúcar como produto agrícola, talvez porque ele apareça como tal na maioria das estatísticas e sistemas de classificação de bens no comércio mundial, assim como muitos economistas brasileiros se referem a ele como produto de exportação no período entre 1870 e 1960.

\section{O PERÍODO 1930-1965: MERCADOS REGULAMENTADOS, ACORDOS FRACASSADOS E A EXPORTAÇÃO DE EXCEDENTES PELO BRASIL}

\subsection{Os mercados mundiais de açúcar entre 1930 e 1965: evolução sob políticas protecionistas, acordos fracassados e arranjos especiais}

Em 1927, ocorreu uma outra tentativa de acordo internacional sobre o mercado de açúcar. Ela fracassou principalmente porque:

"Java, armada com uma variedade de cana de rendimento muito mais alto que o das até então conhecidas, recusou seu apoio à iniciativa, acreditando que poderia produzir mais barato que qualquer outra região e, com isto, assumir o controle do mercado mundial. Ante a recusa de Java, Cuba retirou-se. O acordo não se fez." (Mont'Alegre, set. 1955, 100).

A crise de 1929 parece ter mudado a posição de Java - ou melhor, da Holanda. Em maio de 1931, depois de negociações que vinham desde o ano anterior, foi assinado um acordo (que recebeu o nome de um advogado norte-americano, Chadbourne), que tinha por objetivo equilibrar produção e consumo mundiais. Segundo um importante estudioso da economia açucareira, o plano fracassou por dois motivos principais: primeiro, porque com a crise ocorreu uma queda do consumo per capita em todo o mundo; segundo, porque não incluiu todos os produtores, especialmente os países que não eram exportadores. (Willcox, 1941, p. 60). A história se repetia e, como será visto, se repetirá.

Em 1933, no âmbito da Conferência Monetária e Econômica Mundial, em Londres, iniciaram-se estudos e novas negociações, a partir de uma proposta de Cuba, os quais deram origem ao Acordo Internacional do Açúcar de 1937 e ao Conselho Internacional do Açúcar. Este acordo buscava também promover a expansão do consumo e introduzia uma política de contingenciamento da produção, fundamentado em um sistema de "quotas de exportação", que poderiam ser comple- 
mentadas dependendo das possibilidades de absorção dos países importadores. Tais quotas foram calculadas com base na média das exportações do quinqüênio imediatamente anterior ao acordo. Tal sistema foi inspirado nas idéias do economista norte-americano O. W. Willcox, cuja principal obra, há pouco citada, é uma consagrada defesa do dirigismo na economia açucareira. O problema é que logo iniciou-se a Segunda Grande Guerra, cujo impacto pode ser avaliado pelo seguintes dados: nos seis maiores produtores europeus (Alemanha, Rússia e Ucrânia, França, Tchecoslováquia, Itália e Polônia), a produção da safra 1945/1946 foi 45,8\% da safra de 1939/1940; no caso de Java, Formosa e Filipinas, de apenas 3,2\%. (ver Mont'Alegre, out. 1955).

Tabela 1 - Situações do mercado de açúcar centrifugado, por continente e grupos de países, em 1934/1938 (=100) e 1956/1960 - em mil toneladas métricas

\begin{tabular}{|c|c|c|c|c|c|c|c|c|c|c|}
\hline \multirow{3}{*}{$\begin{array}{l}\text { Continentes, Grupo } \\
\text { e Países (1) }\end{array}$} & \multicolumn{4}{|c|}{ Média do Período 1934 - 1938} & \multicolumn{4}{|c|}{ Média do Período 1956 - 1960} & \multicolumn{2}{|c|}{ Números Índices } \\
\hline & \multicolumn{2}{|c|}{ Consumo } & \multicolumn{2}{|c|}{ Produção } & \multicolumn{2}{|c|}{ Consumo } & \multicolumn{2}{|c|}{ Produção } & \multirow{2}{*}{ Consumo } & \multirow{2}{*}{ Produçãc } \\
\hline & Quantidade & $\%$ & Quantidade & $\%$ & Quantidade & $\%$ & Quantidade & $\%$ & & \\
\hline 1. DAS AMÉRICAS & 8.614 & 35,4 & 8.475 & 34,5 & 15.001 & 33,4 & 17.650 & 39,2 & 174 & 208 \\
\hline - Do Norte & 6.515 & 26,8 & 1.737 & 7,1 & 9.018 & 20,1 & 2.549 & 5,7 & 138 & 147 \\
\hline$->C .,>P: E U A$ & 6.029 & & 1.670 & & 8.240 & & 2.411 & & 137 & 144 \\
\hline - Central & 629 & 2,6 & 4.975 & 20,2 & 1.884 & 4,2 & 9.975 & 22,2 & 300 & 201 \\
\hline >C.: México & 278 & & 318 & & 1.022 & & 1.222 & & 368 & 384 \\
\hline$>P .:$ Cuba & 159 & & 2.741 & & 307 & & 5.605 & & 193 & 204 \\
\hline - Do Sul & 1.470 & 6,0 & 1.763 & 7,2 & 4.099 & 9,1 & 5.126 & 11,4 & 279 & 291 \\
\hline - > C., >P.: Brasil & 649 & & 673 & & 2.177 & & 2.661 & & 335 & 395 \\
\hline 2. EUROPA & 10.825 & 44,5 & 8.648 & 35,2 & 18.942 & 42,2 & 15.912 & 35,4 & 175 & 184 \\
\hline$>$ C., >P.: U.S.S.R. & 1.923 & & 1.924 & & 5.482 & & 5.090 & & 285 & 265 \\
\hline 3. ÁSIA & 3.554 & 14,6 & 4.454 & 18,1 & 7.657 & 17,1 & 6.563 & 14,6 & 215 & 147 \\
\hline - >C.: Índia, >P.56/60 & 975 & & 961 & & 2.228 & & 2.081 & & 229 & 217 \\
\hline - >P. em 34/8-Taiwan & 34 & & 1.030 & & 113 & & 872 & & 332 & 85 \\
\hline 4. ÁFRICA & 844 & 3,5 & 1.111 & 4,5 & 2.530 & 5,6 & 2.433 & 5,4 & 300 & 219 \\
\hline - >C.,>P.: Afr. do Sul & 222 & & 409 & & 661 & & 892 & & 298 & 218 \\
\hline 5. OCEANIA & 477 & 2,0 & 1.892 & 7,7 & 753 & 1,7 & 2.446 & 5,4 & 158 & 129 \\
\hline - >C., >P.: Austrália & 362 & & 769 & & 576 & & 1.323 & & 159 & 172 \\
\hline GRUPO “G7” (2) & 12.156 & 50,0 & 4.129 & 16,8 & 17.233 & 38,4 & 7.366 & 16,4 & 142 & 178 \\
\hline DEMAIS PAÍSES & 12.158 & 50,0 & 20.451 & 83,2 & 27.650 & 61,6 & 37.638 & 83,6 & 227 & 184 \\
\hline MUNDO & 24.314 & 100 & 24.580 & 100 & 44.883 & 100 & 45.004 & 100 & 185 & 183 \\
\hline
\end{tabular}

Fonte: Internacional Sugar Council, 1963, diversas páginas. Manteve-se aqui a alocação do México na América Central, conforme consta nesta publicação.

Notas: (1) > C., >P.: Referem-se aos países maiores consumidores e produtores dos respectivos continentes; (2) Dados dos sete países desenvolvidos (EUA, Alemanha Ocidental, França, Reino Unido, Canadá, Japão e Itália), excluindo-se a área da Alemanha Oriental em 1934/1938.

Na mesma época foi criada a primeira regulamentação bilateral (EUA/outros países) que se tornou conhecida como "mercado preferencial", o qual pode ser visto como um arranjo que deu maior amplitude e institucionalidade aos tratados de reciprocidade anteriormente mencionados. Com o Sugar Act, de 1934, passou-se a especificar as participações de produtores e as condições de 
abastecimento no mercado norte-americano, tendo em conta os diferentes tipos de açúcar e interesses envolvidos na cadeia produtiva. Isto está devidamente tratado na rica obra de DALTON, 1937.

A Tabela 1 apresenta apenas os dados referentes ao açúcar centrifugado. É evidente a diferença de expansão do consumo entre os países desenvolvidos (“G7”) e os não-desenvolvidos, com aqueles tendo expandido suas produções mais do que o consumo. As maiores expansões de mercado ocorreram no México e no Brasil, sendo Taiwan (ou Formosa) a única área em que a produção diminuiu em termos absolutos. Chama a atenção a elevação da produção açucareira na Europa, na qual se destaca o peso relativo da U. R. S. S.

Quanto ao açúcar não-centrifugado, que foi também objeto de levantamento do Conselho Internacional do Açúcar, cabe apenas mencionar que, de modo geral, ele perdeu participação, devido ao efeito-substituição. Na Europa, na África e na Oceania, os dados indicam a não existência de produção e consumo deste açúcar; na Ásia, destacam-se o caso da Índia, maior mercado deste bem, de Burma (hoje Myanma/Birmânia) e do Paquistão, os quais em 1956/1960 produziam e consumiam mais este açúcar, sendo que, na América, o mesmo acontecia apenas nos casos da Colômbia e da Guatemala. Outros dados mostram que, entre 1935/1939 e 1952/1955, a produção de açúcar não-centrifugado elevou-se em 12,3\%, perante uma elevação de 36,7\% do centrifugado. (Brasil Açucareiro, dez. 1955, p. 57).

O caso de Java é importante para ilustrar o modus operandi no mercado de açúcar. Mesmo antes de ter sofrido o impacto da guerra, a produção javanesa havia perdido o mercado da Índia Inglesa em decorrência da alta tarifa aduaneira imposta: "o efeito foi praticamente instantâneo. Surgiram novas fábricas de açúcar branco em toda a parte, tão rapidamente quanto era possível arranjar contratos para a plantação de cana." (Willcox, 1941, p. 49). Quanto à Formosa, tem-se que este país havia se tornado um importante produtor de açúcar a partir de suas relações com o Japão: a produção de cana-de-açúcar multiplicou-se em mais de onze vezes entre 1901/1910 e 1931/1940, constituindo-se um complexo açucareiro apoiado em subsídios e outros incentivos, com a criação de usinas modernas por empresas japonesas. (Johnston e Kilby, 1977, p. 259-260).

Uma estimativa das subvenções totais anuais das políticas açucareiras de alguns países europeus, publicada pela British Sugar Beet Society em meados dos anos trinta, indicou que elas iam de um milhão de libras esterlinas (caso da Dinamarca) a trinta e sete milhões (caso da Alemanha); já os subsídios em shillings por quintal de açúcar produzido variavam de 10,34, na Holanda, a 21,78 na Alemanha. (ver Brasil Açucareiro, jul. 1935, p. 274 e 289).

Em 1948, a pedido do Instituto Cubano de Estabilização do Açúcar, passou a ser examinada pelo Conselho Internacional do Açúcar a revisão das quotas de 1937. As negociações para tanto prolongaram-se até 1953. Não se evitou a repetição do que havia ocorrido no pós-Primeira Grande Guerra, já que tanto os países exportadores como os importadores continuaram aumentando suas produções. Surgiram no cenário novos exportadores, muito em decorrência de três problemas: o primeiro de natureza política, no contexto da Guerra Fria; o segundo de natureza econômica, decorrente dos déficits das balanças comerciais; o terceiro dizia respeito à resistência para a aceitação do dólar como moeda mundial.

As ações da U. R. S. S. e da Inglaterra podem ser vistas como respostas a tais problemas. Este último país, cuja capital era a sede do Conselho Internacional do Açúcar, chegou a sonegar informações sobre o consumo interno de açúcar e a impor restrições a ele. (Mont'Alegre, out. 1955). Mas o que cabe destacar foi a criação de dois novos mercados preferenciais: em 1948, o do Comecom 
- Conselho Econômico de Assistência Mútua -, liderado pela União Soviética que, não abandonando formalmente o acordo, não ratificou os protocolos; em 1951, o da Comunidade Britânica (Commonwealth Sugar Agreement, C.S.A.).

Portanto, não é surpreendente que a assinatura do Acordo em 1953, em Londres, tenha sido uma formalidade, que logo se revelaria problemática. Na avaliação de um analista brasileiro que residia naquela cidade, o critério que predominou na fixação das quotas básicas nesse acordo foi político. Diante disto, alguns países (Brasil, Índia, Peru, Indonésia) não o ratificaram e formaram "um poderoso grupo de franco-atiradores cuja ação retiraria parte substancial do eventual êxito do Acordo." (Mont'Alegre, 1976/1977, p. 197). Esse "critério político" é que parece explicar o acréscimo de 50\% na quota global conferida à Comunidade Britânica entre 1937 e 1953. (conf. dados de Mont'Alegre, out. 1955, p. 86).

Havia outros casos de arranjos e de tratamento diferenciado entre países quanto à circulação de açúcar, reconhecidos igualmente pelo Conselho Internacional do Açúcar, os quais guardam semelhanças com os mercados preferenciais, que eram heranças históricas e que não são aqui tratados, seja por problema de espaço, seja devido sua menor importâncias, por exemplo, Portugal e Holanda, e suas colônias. (ver Mont'Alegre, out. 1964). Os mercados preferenciais tinham como mecanismo de segurança a possibilidade de aquisição e de oferta complementares de açúcar no mercado livre mundial.

Tabela 2 - Exportações mundiais de açúcar entre 1960 e 1965 (números em mil t métricas)

\begin{tabular}{|c|c|c|c|c|c|c|c|}
\hline \multirow[t]{2}{*}{ ANO } & \multirow{2}{*}{$\begin{array}{l}\text { Total do } \\
\text { Consumo } \\
\text { Mundial }\end{array}$} & \multirow{2}{*}{$\begin{array}{c}\text { Total do } \\
\text { Volume } \\
\text { Exportado }\end{array}$} & \multicolumn{2}{|c|}{$\begin{array}{c}\text { Total exportado para Mercados } \\
\text { Preferenciais }\left(^{*}\right)\end{array}$} & \multicolumn{2}{|c|}{$\begin{array}{l}\text { Total exportado para o Mercado } \\
\text { Livre Mundial (MLM) }\end{array}$} & \multirow{2}{*}{$\begin{array}{l}\text { Movimentos } \\
\text { Metrópoles- } \\
\left.\text { Colônias }{ }^{* *}\right)\end{array}$} \\
\hline & & & P. Desenv. & P. em Desenv. & P. Desenv. & P. em Desenv. & \\
\hline 1961 & 53.230 & 20.389 & 1.173 & 9.628 & 4.296 & 4.733 & 2.009 \\
\hline 1962 & 53.601 & 20.465 & 773 & 8.616 & 5.107 & 4.000 & 1.969 \\
\hline 1963 & 54.883 & 18.843 & 889 & 7.016 & 4.541 & 4.498 & 1.899 \\
\hline 1964 & 55.702 & 18.943 & 755 & 6.913 & 4.320 & 5.006 & 1.849 \\
\hline 1965 & 59.560 & 20.516 & 726 & 8.288 & 4.224 & 5.347 & 1.931 \\
\hline
\end{tabular}

Fonte: Mont'Alegre, jul. 1971, diversas páginas.

Notas: (*) Os mercados preferenciais considerados são os do EUA/Sugar Act; o da Comunidade Britânica/CSA; o da U.R.S.S.Cuba/Comecom e o da OCAM/Organização Centro-Africana/Malgache; $\left({ }^{* *}\right)$ Diz respeito à exportação de açúcar de algumas áreas coloniais para suas respectivas metrópoles e/ou vice-versa.

A Tabela 2 traz dados sobre as exportações mundiais de açúcar no início da década de 1960. Pode-se ver que o volume total de açúcar que foi exportado ano a ano situou-se entre $33 \%$ e $38 \%$ do total consumido mundialmente e que as exportações para o mercado livre mundial (MLM) representaram sempre menos de $17 \%$ do mesmo total. $\mathrm{O}$ volume que foi exportado pelos "países em desenvolvimento" no âmbito dos mercados preferenciais mostra a importância desses mercados para tais países. Já o MLM, como observou um autor brasileiro, era "um mercado extremamente deprimido e volúvel, apresentando reações violentas às tensões internacionais e à alterações na oferta $e$ na procura." (Barros, 1968, p. 477).

No caso dos EUA, a importação de açúcar de outros países, ou seja, daqueles não contemplados com preferências no seu mercado, foi de 0,12\% na média de 1934/1938 e de 1951/1955; passando para 5\% em 1960 (ano do rompimento com Cuba) e para 29,3\% em 1961. No caso britânico, a 
participação média do açúcar proveniente dos países do C.S.A. era de 43,4\% em 1951/1953 e chegou a 67,7\% em 1959-1961 no total importado, sendo que, no mesmo período, a produção própria expandiu-se em 32,7\%. No caso da U.S.S.R., cabe destacar que 36\% do açúcar por ela importado no período 1954/1960 foi "não contado para os propósitos" do Acordo Internacional do Açúcar e que sua produção elevou-se em 83\% de 1951/1953 para 1959/1961 (dados de International Sugar Council, 1963, p. 82-86-111).

É inquestionável que, seja pela existência dos mercados preferenciais, seja pelo fracasso dos acordos, os países - principalmente os desenvolvidos - jamais permitiram que o abastecimento de açúcar em suas fronteiras ficasse majoritariamente dependente de "ofertas livres". Reforça isso o fato de que os países da Europa Ocidental expandiram suas produções de açúcar em 89,5\% entre 1937/1938 e 1957/1958. (Mont'Alegre, maio 1975, p. 39). Muitos outros países passaram a produzir em seus territórios o açúcar de que precisavam.

O comportamento dos preços em um e outro mercado constitui uma evidencia do fracasso dos acordos e do sucesso dos arranjos bilaterais. Tomando-se apenas a década de 1950, tem-se que os preços médios anuais do açúcar no mercado livre mundial oscilaram entre 65 e 125 dólares por t. m., muito em decorrência de movimentos especulativos que exigiram "dos vendedores e dos compradores as maiores cautelas, a fim de serem evitados danos e prejuízos vultosos." (dados e trecho extraídos de Watson, 1972, p. 104). Os preços pagos pelos EUA tinham também maior nível médio: enquanto os do mercado livre mundial oscilaram, na média anual entre 1949 e 1954, entre 3,41 e 5,68 centavos de dólar por libra-peso, os daquele situaram-se entre 4,94 e 5,52. (dados de Mont'Alegre, out. 1955, p. 88-89).

Em 1958 foi celebrado um outro acordo. Convém chamar a atenção para o fato de que as negociações iniciaram-se com uma reunião dos países latino-americanos em Havana, em maio daquele ano, que contou com a participação dos EUA, e na qual se explicitou a preocupação com relação ao recente Tratado de Roma (1957), que originou a Política Agrícola Comum (PAC). Este novo acordo partia de uma antiga dificuldade: como distribuir os excedentes dos países exportadores perante a menor necessidade de importação de outros. Repetia-se a história: alguns países, antes importadores, apresentavam-se agora como exportadores. A luta em Cuba levou os EUA a pressionar para evitar o agravamento da situação interna naquele país; além disso, buscou-se reparar os problemas de descontentamento gerados no acordo de 1953. A solução encontrada, agora em Genebra, foi “um pacto em que abundavam as válvulas de escape, as possibilidades de waiver. Dificilmente se conseguiria, com ele, melhorar substancialmente as condições do mercado." (Mont'Alegre, 1976/1977, p. 204).

A situação do mercado mundial de açúcar ficou problemática ao iniciar-se a década de 1960. Isto se deveu principalmente ao rompimento das relações entre o maior produtor (Cuba) e o maior consumidor (EUA) da época. Também deve-se ter em conta que o advento da PAC logo tornaria a Comunidade Econômica Européia uma grande exportadora de açúcar. Em 1962 foi suspensa a vigência das cláusulas econômicas do Acordo de 1958, sendo que um novo acordo só foi assinado em 1968 e entrou em vigor em $1^{\circ}$ de janeiro de 1969.

Mas isto não trouxe calmaria àquele mercado, pelo contrário, ele se tornou, logo depois, ainda mais conturbado em decorrência dos movimentos especulativos com as commodities, que ocorreram no início da década de 1970. Isto acabou beneficiando, no curto prazo, as exportações brasileiras, como será visto na Seção 4.2 deste trabalho. A Seção 4.1 apresentará ainda alguns dados sobre produção e consumo mundiais de açúcar entre 1960/1961 e 1965. 


\subsection{Produção e exportação de açúcar pelo Brasil entre 1930 e 1965: a luta pelo mercado interno e a administração dos excedentes}

A intervenção estatal de âmbito nacional na agroindústria canavieira foi iniciada com a criação da Comissão de Defesa da Produção do Açúcar (CDPA), em 1931, que foi sucedida pelo Instituto do Açúcar e do Álcool (IAA), em 1933. Ela teve como primeiro e principal objetivo conseguir o equilíbrio entre produção e consumo internos, ficando os excessos sob sua responsabilidade. Para isso, utilizou a metodologia proposta por Willcox, definindo-se quotas de produção para cada produtor (de cana e de açúcar). Depois, essa intervenção foi estendida para dar conta dos problemas advindos das relações entre as classes proprietárias do complexo canavieiro do Brasil, o que está tratado com os devidos detalhes nas obras de Szmrecsányi (1979) e Ramos (1999).

Esta orientação da intervenção estatal partiu da constatação de que o açúcar produzido no Nordeste (em Pernambuco, então maior produtor nacional, e Alagoas) havia mesmo perdido o mercado externo. As dificuldades (e prejuízos) com a exportação foram percebidas quando do planejamento da intervenção, o que fica claro na seguinte passagem do livro que passou a ser referência para justificar o caráter inicial da intervenção: “de outra parte, há a notar que a eliminação dos excessos, enquanto não pudermos transformá-los em álcool combustivel, tem de fazer-se pela exportação. Mas esta mesmo, não podemos assegurar que será sempre possível." (Truda, 1971, p. 179. O livro foi escrito em 1934).

A Tabela 3 apresenta a sistematização dos dados do mercado de açúcar no Brasil. Fica evidente o caráter estrutural dos excessos de produção; vê-se que os estoques sempre formaram uma parte substancial da capacidade de oferta e que as exportações não ameaçaram o abastecimento interno. O crescimento do consumo, seja total, seja per capita, não causou problemas ao abastecimento e, na segunda metade dos anos 1950, quando mais se exportou, os estoques também se elevaram, atingindo o maior porcentual em relação ao consumo em 1965.

Tabela 3 - Brasil - Evolução da produção, da exportação, dos estoques e do consumo de açúcar centrifugado - 1935-1965 (médias quinqüenais, em mil toneladas métricas)

\begin{tabular}{lrrrrrrrrr}
\hline Quinqüênio & $\begin{array}{c}\text { Estoque } \\
\text { Inicial }\end{array}$ & Produção & Exportação & $\begin{array}{c}\text { Transformado } \\
\text { em Álcool }\end{array}$ & $\begin{array}{c}\text { Consumo } \\
\text { Aparente }\end{array}$ & $\begin{array}{r}\text { Estoque } \\
\text { Final }\end{array}$ & $\begin{array}{c}\text { Consumo } \\
\text { Per } \\
\text { Capita }\end{array}$ & $\begin{array}{c}\text { Export. S/ } \\
\text { Prod. (\%) }\end{array}$ & $\begin{array}{c}\text { Estoque s/ } \\
\text { Consumo } \\
\text { (\%) }\end{array}$ \\
\hline $1935-39$ & 230,91 & 689,34 & 67,63 & 5,94 & 631,98 & 238,29 & 15,9 & 10,1 & 37,8 \\
$1940-44$ & 287,60 & 875,60 & 43,54 & 9,67 & 814,37 & 295,62 & 18,7 & 4,9 & 36,4 \\
$1945-49$ & 329,07 & $1.204,59$ & 97,66 & 0,14 & $1.099,93$ & 335,93 & 22,7 & 7,3 & 31,0 \\
$1950-54$ & 438,27 & $1.782,97$ & 96,56 & 0 & $1.582,96$ & 541,72 & 28,6 & 4,9 & 33,6 \\
$1955-59$ & 769,76 & $2.011,78$ & 479,0 & 0 & $2.071,15$ & 853,04 & 32,8 & 17,9 & 40,8 \\
$1960-64$ & $1.163,28$ & $3.280,81$ & 567,61 & 0 & $2.675,17$ & $1.201,31$ & 35,2 & 17,3 & 45,1 \\
1965 & $1.449,36$ & $4.660,40$ & 826,76 & 0 & $2.978,70$ & $2.304,30$ & 35,9 & 17,7 & 77,4 \\
\hline
\end{tabular}

Fonte: IAA (Instituto do Açúcar e do Álcool, folha avulsa). 
Tabela 4 - Brasil - Evolução da produção de álcool e \% do anidro, da quantidade entregue para mistura à gasolina e \% de mistura à gasolina (médias quinqüenais de 1930/1931, 1934/1935 a 1960/1961, 1964/1965, em metros cúbicos, por safras e anos civis)

\begin{tabular}{|c|c|c|c|c|c|c|c|}
\hline \multirow[t]{2}{*}{$\begin{array}{l}\text { Quinqüênios } \\
\text { (Safras) }\end{array}$} & \multicolumn{3}{|c|}{$\begin{array}{l}\text { Produção Média de Álcool } \\
\text { (Anidro + Hidratado) }\end{array}$} & \multirow[t]{2}{*}{$\begin{array}{l}\text { Quinqüênios } \\
\text { (Anos Civis) }\end{array}$} & \multicolumn{2}{|c|}{$\begin{array}{c}\text { Quantidade Entregue } \\
\text { para Mistura }\end{array}$} & \multirow[t]{2}{*}{$\begin{array}{l}\% \text { de Mistura à } \\
\text { Gasolina }\end{array}$} \\
\hline & Quantidade & Índice & \% Álcool Anidro & & Norte/Nordeste & Centro/Sul & \\
\hline $1930 / 1-34 / 5$ & $40.056,8$ & 100 & 1,4 & - & - & - & - \\
\hline $1935 / 6-9 / 40$ & $73.862,2$ & 184 & 28,5 & $1936-40$ & $4.517,8\left(^{*}\right)$ & $22.081,6$ & 15,3 \\
\hline $1940 / 1-44 / 5$ & $130.344,2$ & 325 & 44,3 & $1941-45$ & $12.609,7$ & $28.663,4$ & 42,0 \\
\hline $1945 / 6-9 / 50$ & $134.074,6$ & 335 & 33,1 & $1946-50$ & $20.996,5$ & $16.817,5$ & 15,4 \\
\hline $1950 / 1-54 / 5$ & $224.057,4$ & 559 & 39,9 & $1951-55$ & $49.982,0$ & $50.111,4$ & 15,2 \\
\hline 1955/6-9/60 & $370.137,0$ & 924 & 57,8 & $1956-60$ & $71.174,3$ & $132.211,8$ & 18,4 \\
\hline 1960/1-64/5 & $403.996,2$ & 1.009 & 33,6 & $1961-65$ & $43.412,2$ & $69.135,4$ & 13,8 \\
\hline
\end{tabular}

Fonte: IAA (Anuários Açucareiros, vários números e folhas avulsas). Nota: (*) Média do triênio 1938-40.

Cabe destacar a relação entre o mercado de açúcar e o de álcool no Brasil, para o que contribui a Tabela 4. A produção de álcool anidro (denominado de “álcool-motor" no período aqui analisado) foi vista como a válvula de escape mais importante para diminuir e/ou evitar o crescimento dos excedentes de açúcar. Como os dados da Tabela 3 mostram, chegou-se a transformar açúcar em álcool-motor (ou carburante). Esta transformação e, mais ainda, a produção de tal álcool sofreram o impacto da dificuldade de importação de benzeno durante a guerra.

Depois dela, não mais se lançou mão daquela transformação, principalmente porque a produção de açúcar no Brasil esteve associada, desde então, ao aproveitamento do chamado "mel rico" para a produção de álcool (anidro e/ou hidratado), que, entre 1930 e 1975, pode ser considerado o principal subproduto da agroindústria canavieira do Brasil, especialmente em São Paulo e no Rio de Janeiro. Quando as usinas e engenhos não possuíam destilarias anexas (situação mais comum no Nordeste), o IAA se encarregava de comprar este mel, processando-o em suas destilarias ou vendendo-o no mercado externo. Assim, consolidou-se uma oferta interna de álcool hidratado que pode atender às necessidades de seu uso industrial, doméstico e farmacêutico.

Cabe considerar também, para ressaltar a importância do mercado interno para o açúcar brasileiro, as relações entre o País e os acordos internacionais e mercados preferenciais tratados na parte anterior.

O Brasil não participou do "Plano Chadbourne": como visto, o Peru foi o único país da América do Sul que dele fez parte. Quanto ao acordo de 1937, ocorreu que, embora cogitada desde o início, a participação brasileira só se efetivou tardiamente, fundamentalmente porque a quota que se aventou inicialmente para o País era muito pequena (36.000 t), tendo motivado a seguinte pergunta por parte do primeiro presidente do IAA: "que faríamos do excedente dos seiscentos mil sacos a que, por convenção internacional, ficaria, então, restringida a exportação brasileira?" (Truda, 1971, p. 179-180). A quota que acabou sendo destinada ao Brasil foi de 60 mil t anuais, a qual significou um número acima da média exportada entre 1932 e 1936, que foi de 51.909 t, conforme indicam os 
números da Tabela 5, que contém dados sobre a evolução e distribuição das exportações de açúcar pelo Brasil entre 1930 e 1965.

Tabela 5 - Brasil - Evolução e distribuição das exportações de açúcar (todos os tipos), por continentes e principais destinos - 1930 - 1965 (em t. m.)

\begin{tabular}{|c|c|c|c|c|c|c|c|c|c|}
\hline \multirow[t]{2}{*}{ Ano } & \multirow{2}{*}{$\begin{array}{l}\text { Para a } \\
\text { Europa }\end{array}$} & \multicolumn{2}{|c|}{ Para as Américas } & \multirow{2}{*}{$\begin{array}{l}\text { Para a } \\
\text { África }\end{array}$} & \multicolumn{2}{|c|}{ Para a Ásia } & \multirow{2}{*}{$\begin{array}{c}\text { P/ Maior } \\
\text { Importador (1) }\end{array}$} & \multirow[t]{2}{*}{ TOTAL (3) } & \multirow[t]{2}{*}{$\%(4$} \\
\hline & & do Sul & do Norte & & Japão & Restante & & & \\
\hline 1930 & 82.179 & 2.277 & 0 & 0 & 0 & 0 & 74.784 (I) & 84.456 & 78 \\
\hline 1931 & 10.159 & 937 & 0 & 0 & 0 & 0 & 9.907 (I) & 11.096 & 55 \\
\hline 1932 & 35.859 & 4.601 & 0 & 0 & 0 & 0 & $35.443(I)$ & 40.460 & 60 \\
\hline 1933 & 24.790 & 680 & 0 & 0 & 0 & 0 & $24.790(I)$ & 25.470 & 71 \\
\hline 1934 & 23.494 & 403 & 0 & 0 & 0 & 0 & 23.494 (I) & 23.897 & 85 \\
\hline 1935 & 71.305 & 15.586 & 0 & 0 & 0 & 0 & 71.275 (I) & 86.891 & 87 \\
\hline 1936 & 82.313 & 515 & 0 & 0 & 0 & 0 & $82.177(I)$ & 82.828 & 100 \\
\hline 1937 & 0 & 298 & 0 & 0 & 0 & 0 & $192(U)$ & 298 & 64 \\
\hline 1938 & 7.620 & 463 & 0 & 0 & 0 & 0 & $7.620(I)$ & 8.083 & 100 \\
\hline 1939 & 41.948 & 6.406 & 0 & 0 & 0 & 0 & $40.070(I)$ & 48.354 & 96 \\
\hline 1940 & 61.382 & 4.751 & 0 & 0 & 0 & 0 & $23.185(\mathrm{~B})$ & 66.133 & 44 \\
\hline 1941 & 10.840 & 12.033 & (60) (2) & 2.032 & 0 & 0 & $11.808(U)$ & 24.965 & 75 \\
\hline 1942 & n. d. & n. d. & n. d. & n. d. & n. d. & n. d. & n. d. & 46.155 & 46 \\
\hline 1943 & 225 & 22.941 & $6 / E$ & 0 & 0 & 0 & $12.000(\mathrm{~A})$ & 23.172 & 0 \\
\hline 1944 & 0 & 57.789 & 0 & 0 & 0 & 0 & $31.559(U)$ & 57.789 & 4 \\
\hline 1945 & 1.502 & 23.592 & 0 & 0 & 0 & 0 & $21.592(U)$ & 25.094 & 25 \\
\hline 1946 & 4.980 & 15.450 & $1 / \mathrm{E}$ & 0 & 0 & 0 & $9.116(U)$ & 20.431 & 50 \\
\hline 1947 & 18.910 & 36.363 & $3.000 / E$ & 500 & 0 & 3.420 & $24.000(U)$ & 62.193 & 39 \\
\hline 1948 & 168.155 & 71.050 & 0 & 120 & 0 & 102.573 & $87.061(\mathrm{~F})$ & 341.898 & 39 \\
\hline 1949 & 39.786 & 614 & 0 & 0 & 0 & 16.089 & $10.748(\mathrm{~F})$ & 56.519 & 19 \\
\hline 1950 & 0 & 526 & 0 & 0 & 0 & 23.500 & $18.000(\mathrm{~K})$ & 24.026 & 0 \\
\hline 1951 & 17.829 & 553 & 0 & 0 & 960 & 0 & $10.954(\mathrm{P})$ & 19.344 & 5 \\
\hline 1952 & 9.950 & 562 & 0 & 0 & 33.980 & 0 & $33.980(\mathrm{~J})$ & 44.492 & 99 \\
\hline 1953 & 185.217 & 27.306 & 0 & 21.496 & 9.331 & 3.160 & $99.352(\mathrm{I})$ & 246.534 & 78 \\
\hline 1954 & 35.740 & 32.036 & 0 & 0 & 82.745 & 0 & $82.745(\mathrm{~J})$ & 150.521 & 98 \\
\hline 1955 & 282.072 & 82.487 & 0 & 0 & 126.940 & 89.484 & $126.940(\mathrm{~J})$ & 580.983 & 74 \\
\hline 1956 & 4.428 & 14.803 & 0 & 0 & 0 & 4.150 & $14.545(U)$ & 23.381 & 81 \\
\hline 1957 & 224.726 & 50.800 & 0 & 74.911 & 10.631 & 47.886 & 139.788 (I) & 408.954 & 81 \\
\hline 1958 & 274.484 & 127.932 & 0 & 78.384 & 89.528 & 205.890 & $99.431(\mathrm{C})$ & 776.218 & 84 \\
\hline 1959 & 237.950 & 94.117 & $10.537 / \mathrm{E}$ & 59.514 & 66.193 & 138.052 & $118.079(\mathrm{~S})$ & 606.423 & 79 \\
\hline 1960 & 192.079 & 139.597 & 103.423/E & 31.566 & 288.261 & 101.734 & $288.261(\mathrm{~J})$ & 856.720 & 89 \\
\hline 1961 & 41.207 & 68.124 & 293.238/E & 49.176 & 258.638 & 34.481 & $293.238(\mathrm{E})$ & 744.864 & 100 \\
\hline 1962 & 0 & 43.823 & 372.798 & 0 & 21.085 & 40.881 & $361.532(\mathrm{E})$ & 478.587 & 99 \\
\hline 1963 & 28.972 & 20.017 & 421.903 & 0 & 0 & 21.088 & $421.903(\mathrm{E})$ & 491.980 & 90 \\
\hline 1964 & 58.150 & 25.926 & 163.631 & 20.945 & 0 & 0 & $163.631(\mathrm{E})$ & 268.652 & 96 \\
\hline 1965 & 119.372 & 124.557 & 334.910 & 94.358 & 23.418 & 130.141 & $326.196(\mathrm{E})$ & 826.756 & 94 \\
\hline
\end{tabular}

Fonte: IAA, Anuários Açucareiros de 1935 a 1967.

Notas: 1. Maiores importadores: $\mathrm{I}=$ Inglaterra; $\mathrm{U}=$ Uruguai; $\mathrm{B}=$ Bélgica; $\mathrm{A}=$ Argentina; $\mathrm{F}=$ França; $\mathrm{K}=\mathrm{Hong}$ Kong; $\mathrm{P}$ = Portugal; $\mathrm{J}=$ Japão; $\mathrm{C}=$ China; $\mathrm{S}=$ Sri Lanka (ex-Ceilão); E =Estados Unidos da América; 2 . Refere-se à exportação para as Antilhas Inglesas; 3. Inclui as seguintes quantidades a título de donativos: 30 (1949); 2 (1951); 24 (1953); 60 (1959 e 1960); 4. \% de açúcar bruto, demerara e mascavo.

Quanto ao mercado preferencial norte-americano, ocorreu que o sistema de quotas de fornecimento externo do Sugar Act praticamente deixou o Brasil de fora: a quota atribuída ao País para 
1935 foi de 791 libras ou de 360 k. Como observou o autor há pouco citado, "uma quota insuficiente, talvez, até mesmo para remessa de amostras." (Truda, 1971, p. 182).

Os dados da Tabela 5 revelam que a Inglaterra foi, até o início da guerra, o principal comprador, o que se deveu ao tamanho de seu mercado, um dos maiores do mundo naquela época. Esta exportação poderia ser maior se tal país não tivesse implementado, a partir de 1924, uma política de apoio com subsídios, visando à expansão de sua produção interna de açúcar de beterraba, que fez com que ela saltasse das 3.500 t, na safra 1913/1914, para 27 mil na de 1924/1925, e para 500 mil t na safra de 1933/1934. (Cabral, 1936, p. 252). Como se observa, as exportações foram predominantemente de açúcar bruto (quase totalmente demerara), sendo que, apenas na guerra, exportamos açúcar mais processado, principalmente cristal. Os dados do IAA ainda mostram que a primeira exportação de açúcar refinado ocorreu em 1942, que nunca houve exportação para o México e que as vendas para a Europa (inclusive Islândia) concentraram-se na área ocidental.

Os dados das tabelas mostram que as exportações absorviam pequena parcela da produção e foram extremamente irregulares. O Uruguai aparece diversas vezes, entre 1937 e 1947, como nosso principal comprador, especialmente nos anos em que as exportações foram baixas. O destaque na década de 1950 ficou com o Japão, com aquisições também muito irregulares, evidenciando o caráter especulativo do mercado livre mundial. Como se nota, as exportações alcançaram outro nível médio apenas no final dos anos 1950 e, mais especificamente, depois que os EUA bloquearam, em 1960, a entrada do açúcar cubano em seu território, o que permitiu ao Brasil conseguir, em 1962, uma quota expressiva no mercado norte-americano, a qual o IAA destinou prioritariamente ao açúcar produzido por Estados do Nordeste, por ser a região produtora mais pobre. Em meados dos anos 1960, aquela quota era de 360 mil t. (ver Barros, 1968, p. 476-477).

Além de irregulares, as exportações apresentaram, na maior parte do período aqui considerado, preços gravosos. O Anuário Açucareiro do IAA de 1940 (p. 94) contém duas tabelas que evidenciam essa gravosidade: para seis safras entre 1931/1932 e 1939/1940, ocorreram déficits que representaram, em média, 39\% do "valor da exportação" (preço de aquisição pago pela CDPA/IAA + despesas até o destino).

A desagregação das quantidades exportadas segundo suas origens permite estabelecer suas relações com as produções dos respectivos Estados. Os dados da Tabela 6 tornam evidente que as exportações foram mais importantes para os dois Estados do Nordeste. O que se destaca é a grande elevação da produção do Estado de São Paulo na década de 1950. 
Tabela 6 - Brasil - Evolução da produção (em t) dos principais Estados produtores e porcentual exportado (médias dos quinqüênios, associando anos civis a safras)

\begin{tabular}{|c|c|c|c|c|c|c|c|c|}
\hline \multirow{2}{*}{$\begin{array}{l}\text { Anos Civis - Anos } \\
\text { Safras }\end{array}$} & \multicolumn{2}{|c|}{ Pernambuco } & \multicolumn{2}{|c|}{ Alagoas } & \multicolumn{2}{|c|}{ São Paulo } & \multicolumn{2}{|c|}{ Rio de Janeiro } \\
\hline & Produção & $\%$ Exp. & Produção & $\%$ Exp. & Produção & $\%$ Exp. & Produção & $\%$ Exportado \\
\hline $1930 / 4-1929 / 30-33 / 4$ & $217.078,0$ & 12,8 & $61.101,2$ & 9,4 & $87.484,8$ & 0,0 & $100.878,0$ & 0,6 \\
\hline 1935/9-1934/5-38/9 & $228.401,8$ & 13,6 & $66.856,0$ & 11,4 & $128.786,8$ & 0,0 & $133.040,4$ & 0,0 \\
\hline $1940 / 4-1939 / 40-43 / 4$ & $299.159,6$ & 8,8 & $93.487,4$ & 13,0 & $155.197,6$ & 0,0 & $153.777,0$ & 0,2 \\
\hline 1945/9-1944/5-48/9 & $372.973,6$ & 17,2 & $112.162,0$ & 13,4 & $261.292,6$ & 0,1 & $207.059,6$ & 4,6 \\
\hline $1950 / 4-1949 / 50-53 / 4$ & $495.369,2$ & 14,6 & $124.788,6$ & 13,0 & $502.776,6$ & 0,0 & $263.706,8$ & 0,0 \\
\hline 1955/9-1954/5-58/9 & $655.132,2$ & 35,6 & $198.299,8$ & 30,2 & $978.277,8$ & 15,4 & $317.056,0$ & 7,8 \\
\hline $1960 / 4-1959 / 60-63 / 4$ & $730.563,6$ & 41,4 & $263.797,0$ & 39,4 & $1.389 .271,2$ & 10,2 & $387.316,2$ & 5,8 \\
\hline $1965-1964 / 5$ & $792.286,0$ & 61,3 & $309.657,0$ & 53,6 & $1.608 .870,0$ & 10,9 & $428.676,0$ & 0,0 \\
\hline
\end{tabular}

Fonte: IAA (Anuários Açucareiros e folhas avulsas).

O mercado interno de açúcar foi marcado, conforme mostrado em Ramos (1999, p. 73-74), por uma luta entre produtores (engenhos x usinas) e entre produtos (açúcares centrifugados/brancos x açúcares não-centrifugados/escuros). Tal luta pode ser resumida no confronto "açúcar de usina $\mathrm{x}$ açúcar de engenho", a qual perdurou até o final do período aqui analisado, quando ainda operavam muitos engenhos no País, principalmente nas áreas mais afastadas do litoral, mesmo em São Paulo. O açúcar demerara e o cristal são tipos centrifugados e típicos das usinas, as quais podem possuir refinarias anexas, obtendo-se o refinado a partir do cristal. (ver Carneiro, 1970). O açúcar não-centrifugado é um produto típico dos engenhos, embora não se resuma a isso a distinção entre engenho e usina, devendo-se ter em conta outros aspectos - escala de produção e a fonte de energia.

Ilustram a referida luta os seguintes dados, todos retirados dos Anuários Açucareiros do IAA (diversos anos): em 1938 haviam 18.148 engenhos de açúcar registrados junto ao IAA; em 1965, esse número caiu para 12.096; a produção das usinas, na média do triênio das safras 1929/1930, 1930/1931, 1931/1932, significou 52\% do total produzido no Brasil, elevando-se para $76 \%$ em 1945/1946, 1946/1947, 1947/1948; o consumo per capita do "açúcar de usina” elevou-se, entre 1938 e 1947, de 16,1 para $22 \mathrm{~kg}$, sendo que o de “açúcar de engenho" caiu de 7,5 para 6,6 kg. Lamentavelmente, a comparação termina em 1948, já que o IAA não recebeu mais as informações sobre a produção dos engenhos, cuja apuração era de responsabilidade do Ministério da Agricultura (O IAA era vinculado ao Ministério da Indústria e Comércio). Na guerra, faltou açúcar branco (cristal e refinado) em São Paulo, com o que se expandiu o consumo de açúcar escuro, sendo que este Estado também processava açúcar nordestino em suas refinarias.

A luta foi vencida pelas usinas, sendo que as razões disso guardam relação com as que levaram o Brasil a perder o mercado externo de açúcar. Em boa medida, aquela luta também podia ser vista como uma disputa entre produções regionais, tendo São Paulo saído vitorioso principalmente porque o mercado interno concentrou-se às portas de suas fábricas, mas não apenas por isso. (ver Ramos, 1983, cap. I). A vitória paulista fica bem ilustrada nos seguintes dados: na média do triênio 1935/1937, São Paulo "importou” nada menos do que 93,6\% em relação ao produzido; já no triênio 1960/1962, tal média foi de 4,5\%. (ver Ramos, 1983, p. 4). 
Tabela 7 - Brasil - Evolução da quantidade (em t) no comércio interno de açúcar (todos os tipos), participação de São Paulo + Distrito Federal e relação (\%) com as quantidades exportadas (médias quinqüenais do período 1935 - 1962).

\begin{tabular}{|c|c|c|c|c|c|c|c|}
\hline \multirow{2}{*}{$\begin{array}{l}\text { Quinqüê- } \\
\text { nios }\end{array}$} & \multicolumn{2}{|c|}{ Total "Importado" } & \multirow{2}{*}{$\begin{array}{l}\text { Quant. Exp./ } \\
\text { Quant. Com. } \\
\text { Interno (\%) }\end{array}$} & \multirow{2}{*}{$\begin{array}{l}\text { Quinqüê- } \\
\text { nios }\end{array}$} & \multicolumn{2}{|c|}{ Total "Importado" } & \multirow{2}{*}{$\begin{array}{c}\text { Quantidade } \\
\text { Exportada/Quant. } \\
\text { Comércio Interno (\%) }\end{array}$} \\
\hline & Quantidade & $\% \mathrm{SP}+\mathrm{DF}$ & & & Quantidade & $\% \mathrm{SP}+\mathrm{DF}\left({ }^{*}\right)$ & \\
\hline $1935-39$ & 435.972 & 58,3 & 10,4 & $1950-54$ & 821.374 & 36,2 & 11,5 \\
\hline $1940-44$ & 546.960 & 56,0 & 8,0 & $1955-59$ & 1.004 .866 & 34,2 & 50,6 \\
\hline $1945-49$ & 626.904 & 49,8 & 15,5 & $1960-62$ & 1.142 .890 & 27,6 & 61,2 \\
\hline
\end{tabular}

Fonte: IAA (Anuários Açucareiros e folhas avulsas).

Nota: (*) Depois de 1960, o Distrito Federal aqui considerado passou a ser o Estado da Guanabara. Os dados estão disponíveis apenas até 1962 .

Evidentemente, o comércio dentro do País não ocorria apenas entre Pernambuco e São Paulo, e sim entre a Região Nordeste e a Sudeste, com concentração da circulação interna nas duas áreas de maior urbanização (Estado de São Paulo e Distrito Federal/Estado da Guanabara). Nos dados da Tabela 7 fica devidamente destacada a maior importância do comércio interno, seja em termos de quantidades, seja em termos de estabilidade, já que a variação do porcentual da relação entre as quantidades (última coluna) deve-se às oscilações das quantidades exportadas.

Contribuiu para o processo que estamos analisando o comportamento dos preços do açúcar no mercado interno. Dados do IAA mostram que, no período de 1933 a 1948, tal preço foi um dos mais estáveis quando comparado com os preços de diversos outros gêneros alimentícios (ver Anuário Açucareiro, edições de 1942/1944 e 1948/1949). Já entre 1952 e 1962, o preço real do açúcar cristal standard manteve-se relativamente estável, tendo se situado bem acima do seu nível inicial apenas em 1956, e um pouco acima em 1954 e 1957. (conf. Ramos, 1983, p. 21).

As negociações para o acordo internacional de 1953 significaram para o Brasil um processo semelhante ao que havia ocorrido entre 1933 e 1937. O País ameaçou dele não participar, pois, tendo pleiteado inicialmente uma quota de, no mínimo, 400.000 t. m., recebeu como “oferta” uma quota de 100.000 t. m.. Acabou sendo um dos signatários com uma quota de 175.000 t. m., o que foi considerado pelo chefe da delegação brasileira "uma grande vitória (...) pois, é uma válvula de garantia para os inevitáveis excessos da produção açucareira nacional." (conf. Dé Carli, 1953, p. 65). Tal quota estava abaixo do que o País exportou em 1948, mas acima da quantidade média exportada entre 1948 e 1952 (97.256 t. m.). Porém o País logo se mostraria insatisfeito com aquela quota, deixando o acordo em 1955. Depois, assinou em 1956 um protocolo de intenção, no qual sinalizava aceitar uma quota de 550 mil t. m., o que antecipou sua volta ao Conselho Internacional de Açúcar. Especialmente o Brasil, mas também o Peru e outros países, acabaram recebendo uma atenção especial no novo acordo de 1958, pois, embora tivesse sido previamente definido que os exportadores de 1953 não teriam suas quotas majoradas, algumas o foram, sendo que a do Brasil foi a que mais aumentou, passando a ser de 550.000 t. m., cabendo destacar que, mesmo assim, ainda houve tentativa de se conseguir uma de 700 mil t. (ver Mont'Alegre, 1976/1977, p. 204). 
Tabela 8 - Evolução da distribuição das quotas dos acordos internacionais sobre o açúcar - 1937 - 1953 - 1958 (em mil toneladas métricas)

\begin{tabular}{|c|c|c|c|c|c|}
\hline \multicolumn{2}{|c|}{ Acordo de 1937} & \multicolumn{2}{|c|}{ Acordo de 1953} & \multicolumn{2}{|c|}{ Acordo de 1958} \\
\hline 1. Países Baixos (*) & 1.050 & 1. Cuba & 2.250 & 1. Cuba & 2.415 \\
\hline 2. Cuba & 940 & 2. Formosa & 600 & 2. Formosa & 655 \\
\hline 3.Rep. Dominicana & 400 & 3.Rep. Dominicana & 600 & 3. Rep. Dominicana & 655 \\
\hline 4.Perú & 330 & 4. Perú & 280 & 4. BRASIL & 550 \\
\hline 5.Tchecoslováquia & 250 & 5. Tchecoslováquia & 275 & 5. Perú & 490 \\
\hline 6. U.R.S.S. & 230 & 6.Indonésia & 250 & 6. Indonésia & 350 \\
\hline 7.Alemanha & 120 & 7, Polônia & 220 & 7. Tchecoslováquia & 275 \\
\hline 8.Polônia & 120 & 8. U.R.S.S. & 200 & 8. Polônia & 220 \\
\hline 9. BRASIL & 60 & 9. BRASIL & 175 & 9. U.R.S.S. & 200 \\
\hline 10. Hungria & 40 & 10. Alemanha Oriental & 150 & 10. Alemanha Oriental & 150 \\
\hline 11. Haiti & 32,5 & 11. México & 75 & 11. Dinamarca & 75 \\
\hline 12. Portugal & 30 & 12. Dinamarca & 70 & 12. México & 75 \\
\hline 13. Bélgica $\left({ }^{* *}\right)$ & 20 & 13. Bélgica $\left(^{* \star}\right)$ & 50 & 13. Bélgica $\left.{ }^{* *}\right)$ & 55 \\
\hline- & - & 14. Haiti & 45 & 14. Haiti & 45 \\
\hline- & - & 15. Hungria & 40 & 15. Hungria & 40 \\
\hline- & - & 16. Outros $\left(^{* * *}\right)$ & 105 & 16. Outros $\left(^{* * *}\right)$ & 165 \\
\hline TOTAL & $3.622,5$ & TOTAL & 5.385 & TOTAL & 6.415 \\
\hline
\end{tabular}

Fontes: Mont'Alegre, out. 1955 e dez. 1958.

Notas: $\left(^{*}\right)$ Incluem territórios e/ou possessões de ultramar (basicamente, Java); ${ }^{* *}$ ) Inclui o Congo Belga.

(**) Em 1953, refere-se a: Holanda, 40; Colômbia, 5; França, 20; Filipinas, 20, Iugoslávia, 20. Em 1958 a: Colômbia, 5; Filipinas, 25; França, 20; Índia, 25; Itália, 20, Países Baixos, 40; Portugal, 20 e Turquia, 10.

Numa reunião preparatória do acordo de 1958 em Havana, o Brasil havia deixado claro que queria participar do mercado preferencial norte-americano. A revolução cubana tornou isso possível e o País voltou a ser, após mais de um século, um exportador importante, na mesma época em que São Paulo também já não podia mais contar apenas com o seu mercado local e regional para realizar parte significativa de sua produção. A entrada do açúcar brasileiro no mercado preferencial norte-americano foi muito importante, seja pela garantia de realização de parte significativa da produção, seja porque, como mostrado anteriormente, neste mercado os preços tinham maiores níveis e eram menos instáveis. As vendas para este mercado representaram $84 \%$ das vendas para o mercado livre mundial na média do período 1960-1965.

A Tabela 8 apresenta a distribuição e a evolução das quotas dos países exportadores signatários dos acordos tratados. A quota brasileira elevou-se em $817 \%$ no período, a de Cuba em $157 \%$ e a da República Dominicana em 64\%. Percebe-se também o surgimento de novos exportadores. A quarta posição na tabela não significava que o Brasil fosse o quarto maior exportador para o mercado livre mundial: na verdade, ocupava a sétima posição, se tomada a média das vendas para este entre 1960 e 1965. (conf. dados apresentados por Mont'Alegre, 1973, p. 40-41). Isto se deve ao fato de que os acordos sobre tal mercado não levavam em conta a participação dos países exportadores deles não participantes, como é o caso dos países pertencentes à comunidade britânica. A Comunidade Econômica Européia (CEE) era, tomando-se aquela média, a quarta maior exportadora para o MLM, 
situando-se após Cuba, Austrália e Formosa/Taiwan, e seguida da Polônia, da Tchecoslováquia e do Brasil.

Tabela 9 - Os dez maiores países produtores de açúcar centrifugado em 1929 e em 1965 (produção em milhões de toneladas métricas, tanto açúcar de cana como de beterraba)

\begin{tabular}{llc|clc}
\hline & \multicolumn{2}{l|}{ MÉDIA DAS SAFRAS 1927/28-28/29-29/30 } & \multicolumn{3}{c}{ DADOS DA SAFRA 1965/66 (previsão) } \\
\cline { 2 - 6 } N. & PAíSES & Quantidades & N. & PAÍSES & Quantidades \\
\hline 1 & Cuba & 4,69 & 1 & U. R. S. S. & 8,30 \\
2 & Java & 2,97 & 2 & Cuba & 6,05 \\
3 & Índia Inglesa & 2,95 & 3 & EUA (Inclui o Havaí) & 4,80 \\
4 & EUA (inclui Havaí) & 1,91 & 4 & Brasil & 3,70 \\
5 & Alemanha & 1,86 & 5 & Índia & 3,30 \\
6 & Rússia + Ucrânia & 1,32 & 6 & França & 2,43 \\
7 & Tchecoslováquia & 1,13 & 7 & China & 2,20 \\
8 & Brasil & 0,95 & 8 & Áustria & 2,24 \\
9 & França & 0,91 & 9 & México & 2,10 \\
10 & Japão + Formosa/Taiwan & 0,85 & 10 & Polônia (e também Filipinas) & 1,75 \\
\hline
\end{tabular}

Fontes: Ramos, 2001 e Brieger, 1967.

No início da década de 1960, o IAA passou a se preocupar mais com a exportação, seja em função da entrada do açúcar brasileiro no mercado norte-americano, seja em função do fato de que havia um pessimismo quanto ao abastecimento futuro, o que ficava claro nas análises inclusive de organismos internacionais (exemplo da FAO), prevendo-se uma escassez generalizada e, portanto, um longo período de preços elevados no mercado livre mundial. Assim, o IAA criou, em 1961, sua Divisão de Exportação, embora há muito tempo tivesse um escritório de representação em Londres. Esta nova orientação quanto ao possível destino de boa parte da produção nacional terá importantes desdobramentos na evolução futura e na estrutura de produção de açúcar e de álcool do País, como será visto a seguir.

Contudo, em meados da década de 1960, o Brasil já era o quarto maior produtor mundial de açúcar centrifugado, com um total produzido quase quatro vezes maior do que o de 1929, como mostram os dados da Tabela 9.

\section{O PERÍODO 1966-1980: A INSTABILIDADE NOS MERCADOS MUNDIAIS E A EVOLUÇÃO DA AGROINDÚSTRIA CANAVIEIRA DO BRASIL: DA EXPORTAÇÃO DE AÇÚCAR AO PROÁLCOOL}

\subsection{Euforia e instabilidade nos mercados mundiais de açúcar}

Como afirmado anteriormente, os mercados mundiais de açúcar encontravam-se conturbados no início da década de 1960, o que prosseguiu até meados da década seguinte, configurando um longo período de significativa instabilidade. Isto esteve relacionado com as expectativas pessimistas 
quanto aos seus abastecimentos no futuro imediato, já que se constatou que o consumo de açúcar estava em grande ascensão no período, o que os números da Tabela 10 evidenciam com clareza. Assim, o açúcar, junto com outras commodities, foi alvo de fortes especulações.

Pode-se, contudo, analisar os dados com maior especificidade. São facilmente perceptíveis dois movimentos quanto ao consumo: o primeiro deles é que o maior crescimento ocorreu durante a década de 1960; o segundo é que esse maior crescimento se fez mais presente nas regiões abaixo do Equador e, principalmente, nos "países em desenvolvimento". A continuidade de tal crescimento entre 1970 e 1980 fez com que tais países aumentassem sobremaneira suas importações líquidas. Chama a atenção o aumento do consumo per capita da Ásia entre 1961 e 1970, o que deve ser a causa principal do pessimismo há pouco lembrado quanto ao abastecimento mundial de açúcar. Na América Central e do Sul, assim como na África, tal crescimento continuou até 1980. Destaca-se a retração daquele consumo na América do Norte entre 1970 e 1980. No caso da Oceania, a maior retração ocorreu entre 1965 e 1970.

Tabela 10 - Evolução da produção e consumo de açúcar centrifugado, por regiões, grupos de países e totais (consumo per capita em kg/ano; quantidades totais em mil t. m.)

\begin{tabular}{|c|c|c|c|c|c|}
\hline REGIÕES/MUNDO & 1961 & 1965 & 1970 & 1975 & 1980 \\
\hline \multicolumn{6}{|l|}{ Consumo per capita } \\
\hline - Europa & 35,0 & 36,7 & 39,3 & 38,8 & 41,1 \\
\hline - América do Norte & 47,6 & 47,6 & 52,7 & 42,4 & 41,1 \\
\hline - América Central & 30,1 & 34,2 & 39,2 & 40,3 & 43,8 \\
\hline - América do Sul & 32,7 & 33,8 & 35,2 & 40,7 & 45,9 \\
\hline - Ásia & 5,7 & 6,3 & 8,1 & 8,2 & 8,2 \\
\hline - África & 10,0 & 10,1 & 11,7 & 12,8 & 14,7 \\
\hline - Oceania & 58,6 & 58,8 & 48,7 & 48,6 & 45,8 \\
\hline Média mundial & 17,6 & 18,0 & 19,9 & 19,6 & 20,1 \\
\hline \multicolumn{6}{|l|}{ Totais } \\
\hline - Produção & $52.299\left({ }^{*}=1960\right)$ & 63.790 & 71.142 & 78.846 & 84.514 \\
\hline - Consumo & $49.218\left(^{*}\right)$ & 57.962 & 70.480 & 74.438 & 88.164 \\
\hline \multicolumn{6}{|l|}{ Países Desenvolvidos } \\
\hline Produção & $25.005(48 \%)\left({ }^{*}\right)$ & $30.269(47 \%)$ & $32.893(45 \%)$ & $35.864(44 \%)$ & $38.775(46 \%)$ \\
\hline Consumo & $32.290(67 \%)\left({ }^{*}\right)$ & $39.143(66 \%)$ & $42.970(60 \%)$ & $41.886(54 \%)$ & $46.831(53 \%)$ \\
\hline Consumo per capita & $32,6\left(^{*}\right)$ & 38,2 & 40,1 & 39,9 & 40,1 \\
\hline Importações líquidas (\%) & $11.296(75 \%)\left({ }^{*}\right)$ & $13.524(75 \%)$ & $13.366(73 \%)$ & $15.183(62 \%)$ & $12.890(56 \%)$ \\
\hline Exportações líquidas (\%) & $1.782(12 \%)\left(^{*}\right)$ & $3.240(18 \%)$ & $4.968(25 \%)$ & $2.986(16 \%)$ & $6.379(28 \%)$ \\
\hline \multicolumn{6}{|c|}{ Países em Desenvolvimento } \\
\hline Produção & $27.621(52 \%)\left({ }^{*}\right)$ & $34.296(53 \%)$ & $40.011(55 \%)$ & $45.681(56 \%)$ & $45.740(54 \%)$ \\
\hline Consumo & $16.152(33 \%)\left(^{*}\right)$ & $20.480(34 \%)$ & $29.123(40 \%)$ & $35.447(46 \%)$ & $41.333(47 \%)$ \\
\hline Consumo per capita & $8,1\left(^{*}\right)$ & 9,1 & 11,5 & 12,2 & 12,7 \\
\hline Importações líquidas & $3.716(25 \%)\left({ }^{*}\right)$ & $4.493(25 \%)$ & $5.030(27 \%)$ & $9.215(38 \%)$ & $10.211(44 \%)$ \\
\hline Exportações líquidas & $13.401(88 \%)\left({ }^{*}\right)$ & $15.221(82 \%)$ & $15.054(75 \%)$ & $15.448(84 \%)$ & $16.761(72 \%)$ \\
\hline
\end{tabular}

Fontes: Mont'Alegre, jul. 1971; Szmrecsányi, 1989; FAO, 1985. 
Tabela 11 - Preços do açúcar nos mercados mundiais - 1961 - 1975 (médias anuais em centavos de dólar por libra)

\begin{tabular}{ccccc|ccccc}
\hline ANO & $\begin{array}{c}\text { OIA (Preço } \\
\text { Diário) }\end{array}$ & $\begin{array}{c}\text { L. D. P. } \\
\left({ }^{*}\right)\end{array}$ & $\begin{array}{c}\text { Nova } \\
\text { York }\end{array}$ & $\begin{array}{c}\text { C.S.A. (Preço } \\
\text { Negociado) }\end{array}$ & ANO & $\begin{array}{c}\text { OIA (Preço } \\
\text { Diário) }\end{array}$ & $\begin{array}{c}\text { L. D.P. } \\
\left({ }^{* *}\right)\end{array}$ & $\begin{array}{c}\text { Nova } \\
\text { York }\end{array}$ & $\begin{array}{c}\text { C.S.A. (Preço } \\
\text { Negociado) }\end{array}$ \\
\hline 1961 & 2.75 & 2.72 & 3.59 & 5.64 & 1969 & 3.20 & 3.20 & 3.31 & 4.66 \\
1962 & 2.83 & 2.83 & 2.91 & 5.72 & 1970 & 3.68 & 3.69 & 3.68 & 4.66 \\
1963 & 8.34 & 8.45 & 8.42 & 5.76 & 1971 & 4.50 & 4.52 & 4.52 & 4.66 \\
1964 & 5.77 & 5.82 & 5.80 & 5.76 & 1972 & 7.27 & 7.32 & 7.42 & 5.36 \\
1965 & 2.08 & 2.12 & 2.06 & 5.25 & 1973 & 9.45 & 9.57 & 9.59 & 5.36 \\
1966 & 1.81 & 1.81 & 1.80 & 5.44 & 1974 & 29.66 & 30.11 & 29.91 & 14.23 \\
1967 & 1.92 & 1.95 & 1.93 & 5.44 & $1975\left(^{*}\right)$ & 22.72 & 23.33 & 22.80 & - \\
1968 & 1.90 & 1.90 & 1.92 & 4.66 & & & & & \\
\hline
\end{tabular}

Fonte: Mont'Alegre, jun. 1976.

Notas: $\left.{ }^{*}\right)$ Preços da média de janeiro a setembro, $\left({ }^{*}\right)$ London Daily Price.

Dado o peso dos EUA no contexto da América do Norte, pode-se associar a mencionada retração nesta área ao crescimento do consumo de substitutos do açúcar de cana e de beterraba. Entre eles destaca-se a enorme ampliação do consumo per capita de HFCS (isoglucose de milho) naquele país, o qual passou de 0,59 kg/ano em 1972, para 21,47 em 1980. (dados extraídos de Szmrecsányi, 1989, p. 169). Para isto contribuiu, a partir de 1973, a utilização de "uma nova tecnologia em sua fabricação, permitindo aumentar o volume a custos competitivos.” (Mont'Alegre, jun. 1976, p. 60). Evidentemente, esta competição se fez com os maiores níveis de preços do açúcar centrifugado no período, o que pode ser constatado com base nos dados da Tabela 11.

O que ocorreu foi que à secular tendência de busca e obtenção de auto-suficiência no abastecimento de açúcar, juntou-se um novo movimento: o de "concorrência e substituições que atingem o mercado de açúcar a partir de meados da década de 1970.” (Jank, 1989, p. 30). Como é sabido, este movimento incluiu o advento dos adoçantes artificiais.

Voltando à Tabela 10, chamam a atenção os dados de produção e consumo totais em 1980, indicando um déficit significativo. Isto necessita ser qualificado como um resultado da reversão das expectativas anteriores, por demais pessimistas, como já mencionado, e que estimularam a elevação da produção e, portanto, dos excedentes dirigidos ao MLM. Os efeitos de tal reversão se fizeram sentir na inversão da tendência altista dos preços já a partir do início de 1975, como indicam os dados da Tabela 11. Para tornar esta qualificação mais consistente, cabe mencionar que a maior produção mundial chegou a ser de 90.832 mil toneladas em 1978 e que o maior nível de consumo no período foi o de 1979, tendo atingido um montante de 89.998 mil toneladas, segundo os dados da FAO que foram utilizados na Tabela 10. Evidentemente, cabe lembrar que o açúcar, embora um produto industrial, enfrenta o problema da sazonalidade produtiva em decorrência de fatores climáticos, o que reforça os movimentos especulativos. De qualquer modo, convém mencionar que a estimativa da FAO, segundo Watson (set. 1973, p. 11) era de que o consumo mundial em 1980 seria maior em 23 milhões de toneladas quando comparado ao de 1970, totalizando 93,18 milhões de toneladas.

A Tabela 11 mostra também o comportamento dos preços praticados em Londres, seja no âmbito do C. S. A., seja no tocante às aquisições no mercado livre mundial (preços L. D. P.) e, 
finalmente, os preços desse mercado definidos pela Organização Internacional do Açúcar (OIA). Convém destacar a significativa instabilidade de todos os preços que a tabela apresenta, culminando com seus maiores níveis médios em 1974. Portanto, repetiu-se a história: o acordo de 1968 não conseguiu estabilizar os preços internacionais do açúcar.

"Os preços do açúcar no mercado livre atingiram seu ponto mais elevado em novembro de 1974." (Mont'Alegre, jun. 1976, p. 61). Um mês depois ocorreu a extinção da C. S. A. e a suspensão do mercado preferencial norte-americano. Logo depois, em fevereiro de 1975, foi assinada a Convenção de Lomé, que associou a CEE a países da África, Caribe e Pacífico (que passou a ser conhecida pela sigla ACP). Tal convenção garantiu uma quota de 1,3 milhão de toneladas de açúcar branco ACP no mercado da CEE. "Com isso ficou assegurada continuidade dos suprimentos que anteriormente eram feitos ao Reino Unido sob o Convênio Açucareiro da Comunidade Britânica, resguardada sob a garantia de preços correlatos com o de intervenção praticado na CEE." (Mont'Alegre, jun. 1976, p. 72).

Contudo, o fato de maior alcance do período foi a alteração da participação da CEE no mercado livre mundial: se em 1975 ela foi importadora líquida de 238 mil t, em 1976 ela foi exportadora líquida de 1,2 milhão de te de 2,4 milhões em 1977. (dados extraídos de FAO, 1985, p. 17 e 21). Em 1980/1981, ela já era o segundo maior exportador líquido de açúcar centrifugado, precedida apenas de Cuba. (conforme dados apresentados por Szmrecsányi, 1989, p. 166-167). É evidente que isto não pode ser dissociado do advento da Política Agrícola Comum, como apontando anteriormente.

Em 1977 foi assinado mais um Convênio Internacional do Açúcar, que entrou em vigor em janeiro de 1978. Sua realização contou com a participação ativa dos EUA, que não havia participado do convênio de 1968. (ver FAO, 1985, p. 16-17). Contudo, o problema estava na posição da CEE, que demonstrou "falta de interesse" pelo convênio, o que, é óbvio, não deixava de estar relacionado com as medidas e com os resultados que delas decorreram, conforme há pouco mencionado. Esta é, com certeza, a razão pela qual a referida suspensão da legislação açucareira dos EUA foi temporária.

Tabela 12 - Distribuição das cotas de exportação de açúcar pelo acordo internacional do açúcar, em 1979 (cotas em mil t métricas)

\begin{tabular}{lc|ll|lc}
\hline PÁíSES & COTAS & PAìSES & COTAS & PAÍSES & COTAS \\
\hline 1. Cuba & $2.017,50$ & 10. Guatemala & 244,50 & 19. Suazilândia & 85,57 \\
2. Austrália & $1.997,50$ & 11. Argentina & 166,75 & 20. Moçambique & 81,50 \\
3. BRASIL & $1.915,25$ & 12. Maurício & 142,63 & 21. Bolívia & 73,15 \\
4. Filipinas & $1.141,00$ & 13. El Salvador & 118,18 & 22. Panamá & 71,15 \\
5. Tailândia & $1.020,00$ & 14. Guiana & 118,18 & 23. México & 70,00 \\
6. Rep. Dominicana & 915,00 & 15. Jamaica & 105,95 & 24. Equador & 70,00 \\
7. Índia & 872,18 & 16. Nicarágua & 101,88 & 25. Trinidad y Tobago & 70,00 \\
8. África do Sul & 713,13 & 17. Fiji & 101,87 & & \\
9. Peru & 285,25 & 18. Costa Rica & 85,58 & TOTAL & $12.583,68$ \\
\hline
\end{tabular}

Fonte: Planalsucar, 1979, p. 8.

Não obstante, o Brasil havia se tornado, na época, um dos maiores exportadores de açúcar, tendo sido beneficiado com uma cota de exportação, em 1979, bem maior (em 248\%) que a do último acordo em 1958, como mostram os dados da Tabela 12 em relação aos da Tabela 8. A comparação entre os dados dessas tabelas mostra também que muitos países subdesenvolvidos, prin- 
cipalmente do Caribe, passaram a ser contemplados com cotas e outros, principalmente do leste europeu, deixaram de aparecer na lista. Evidentemente, isto guardou relação com a expansão do bloco liderado pela União Soviética e com as alterações da relação CEE/ACP.

\subsection{A evolução das exportações e da agroindústria canavieira do Brasil: dos excedentes de açúcar à ampliação do mercado de álcool carburante}

Como mencionado há pouco, predominava ainda uma euforia no mercado mundial de açúcar na metade da década de 1960 e mesmo no início da seguinte, dada a estimativa de que, durante um longo tempo, haveria uma situação de escassez. Como já indicado, essa previsão foi compartilhada por diversos especialistas brasileiros, inclusive aqueles vinculados ao IAA. Este foi o motivo pelo qual este órgão implementou, entre 1961 e 1973, um conjunto de medidas destinadas a dotar o complexo canavieiro brasileiro da capacidade para produzir, até o início da década de 1970, o montante de 100 milhões de sacas de açúcar, ou seja, 6 milhões de t. (ver Szmrecsányi, 1979, p. 254-272). Na verdade, o IAA respondia assim à pressão dos produtores, pois eles solicitaram ao "governo a autorização e os meios financeiros necessários para expandirem em mais de $50 \%$ a capacidade produtiva então instalada." (Szmrecsányi e Moreira, 1991, p. 65).

Tabela 13 - Evolução das exportações de açúcar pelo Brasil entre 1966 e 1980 (quantidades em t. m.; preços médios em US $\$ / t$ )

\begin{tabular}{|c|c|c|c|c|c|c|c|}
\hline \multirow[t]{2}{*}{ ANO } & \multirow{2}{*}{$\begin{array}{l}\text { Quantidade } \\
\text { Exportada }\end{array}$} & \multicolumn{2}{|c|}{ Exportado p/o MLM } & \multicolumn{3}{|c|}{ Exportado p/Mercado Preferencial EUA } & \multirow{2}{*}{$\begin{array}{l}\text { \% Exportado } \\
\text { por S. Paulo }\end{array}$} \\
\hline & & Quantidade & Preço médio & Quantidade & Preço Médio & $\%$ Quantidade & \\
\hline 1966 & 1.017 .529 & 521.000 & 46,07 & 496.529 & 126,62 & 48,8 & 34,1 \\
\hline 1967 & 1.010 .856 & 414.115 & 38,87 & 596.741 & 134,29 & 59,0 & 45,4 \\
\hline 1968 & 1.095 .449 & 468.897 & 54,42 & 626.552 & 137,09 & 57,2 & 38,2 \\
\hline 1969 & 1.082 .680 & 416.479 & 50,00 & 666.201 & 146,55 & 61,5 & 15,8 \\
\hline 1970 & 1.149 .907 & 530.723 & 71,35 & 619.184 & 150,13 & 61,5 & 14,8 \\
\hline 1971 & 1.242 .904 & 635.575 & 90,43 & 607.329 & 160,74 & 48,9 & 24,4 \\
\hline 1972 & 2.634 .997 & 2.004 .587 & 154,21 & 630.410 & 178,01 & 23,9 & 46,2 \\
\hline 1973 & 2.970 .588 & 2.522 .485 & 201,34 & 448.103 & 203,78 & 15,1 & 61,9 \\
\hline 1974 & 2.283.195 & 1.578 .951 & 580,93 & 704.244 & 573,47 & 30,8 & 58,2 \\
\hline 1975 & 1.729 .911 & 1.575 .238 & 631,27 & 154.673 & 375,04 & 8,9 & 40,0 \\
\hline 1976 & 1.238 .201 & 1.238 .201 & 250,01 & 0,0 & - & 0,0 & 35,1 \\
\hline 1977 & 2.486 .586 & 1.806 .745 & $(181,96)\left(^{*}\right)$ & 679.841 & n. d. $\left(^{*}\right)$ & 27,3 & 26,3 \\
\hline 1978 & 1.924 .591 & 1.345 .050 & $(172,80)\left(^{*}\right)$ & 579.541 & n. d. $\left(^{*}\right)$ & 30,1 & 17,2 \\
\hline 1979 & 1.941 .589 & 888.353 & $(198,89)\left(\left(^{*}\right)\right.$ & 1.053 .236 & n. d. $\left(^{*}\right)$ & 54,3 & 7,0 \\
\hline 1980 & 2.569 .204 & 1.772 .826 & 494,83 & 796.378 & 496,89 & 31,0 & 28,3 \\
\hline
\end{tabular}

Fonte: IAA (relatórios anuais e out. 1976); Ramos, 1983.

Nota: $\left({ }^{*}\right)$ Trata-se dos preços médios dos dois mercados, pois os relatórios do IAA não apresentaram, nesses anos, os dados de forma a permitir a distinção.

Entre tais medidas cabe aqui destacar a criação, em 1965, de um fundo para financiar a modernização técnico/produtiva das fábricas. Este fundo foi denominado de Fundo Especial de Ex- 
portação (FEE), e era formado por uma taxa ad valorem sobre o preço de exportação de açúcar. Seu montante não foi significativo até o final da década de 1960, exatamente porque tal preço não era alto. Contudo, na primeira metade da década seguinte, ele se situou em patamares muito elevados. Os dados de preços e quantidades exportadas estão na Tabela 13. Em 1980/1981 o Brasil foi o quarto maior exportador líquido de açúcar centrifugado. (conforme Szmrecsányi, 1989, p. 167).

No início da década de 1970, o IAA (com decretos de 1971 e 1973) pôde concretizar o programa de modernização acima referido, imprimindo-lhe, contudo, uma nova orientação: a de sanção e, mais ainda, de promoção de um processo de concentração, tanto industrial como fundiária, que se estendeu até 1977, a partir de quando os recursos do FEE tornaram-se diminutos. A Tabela 14 traz alguns dados sobre esse processo de concentração econômica sancionado pelo Estado ditatorial brasileiro. (para melhor compreensão ver Ramos, 1999, cap. 2, parte 2.3).

Tabela 14 - Porcentagens da produção de cana-de-açúcar segundo estratos de área em São Paulo, Pernambuco e Alagoas (1970 e 1975); evolução da escala de produção das usinas brasileiras (1971/72 e 1978)

\begin{tabular}{|c|c|c|c|c|c|c|c|c|c|c|c|c|c|}
\hline \multicolumn{7}{|c|}{$\begin{array}{l}\text { \% da Produção de Cana nos Principais } \\
\text { Estados Produtores Conf. Estratos }\end{array}$} & \multicolumn{7}{|c|}{$\begin{array}{l}\text { Distribuição do Número de Usinas } \\
\text { Conforme a Escala de Produção }\end{array}$} \\
\hline \multirow{2}{*}{$\begin{array}{l}\text { Estratos (Área } \\
\text { total em há) }\end{array}$} & \multicolumn{3}{|c|}{1970} & \multicolumn{3}{|c|}{1975} & \multirow{2}{*}{$\begin{array}{l}\text { Escala em t } \\
\text { de açúcar }\end{array}$} & \multicolumn{2}{|c|}{$\mathrm{N} /$ Nordeste } & \multicolumn{2}{|c|}{ Centro/Sul } & \multicolumn{2}{|c|}{ Total } \\
\hline & SP & PE & $\mathrm{AL}$ & SP & $\mathrm{PE}$ & $\mathrm{AL}$ & & $1971 / 2$ & 1978 & $1971 / 2$ & 1978 & $1971 / 72$ & 1978 \\
\hline $0-10$ & 1,2 & 2,7 & 1,8 & 0,6 & 2,5 & 1,1 & - de 6 mil & 14 & 5 & 11 & 2 & 25 & 7 \\
\hline $10-100$ & 17,2 & 8,0 & 13,4 & 12,0 & 11,3 & 12,1 & $6-18 \mathrm{mil}$ & 49 & 14 & 74 & 16 & 123 & 30 \\
\hline $100-1.000$ & 44,8 & 73,0 & 60,2 & 40,3 & 72,6 & 56,3 & $18-36$ mil & 26 & 34 & 41 & 23 & 67 & 57 \\
\hline $1.000-10.000$ & 33,2 & 16,3 & 21,1 & 41,7 & 13,4 & 29,1 & $36-60 \mathrm{mil}$ & 8 & 22 & 19 & 54 & 27 & 76 \\
\hline \multirow[t]{3}{*}{ > que 10.000} & 3,6 & - & 3,5 & 5,4 & - & 1,4 & $60-90 \mathrm{mil}$ & - & 12 & 6 & 10 & 6 & 22 \\
\hline & & & & & & & + de 90 mil & - & 1 & 1 & 13 & 1 & 14 \\
\hline & & & & & & & TOTAIS & 97 & 88 & 152 & 118 & 249 & 206 \\
\hline
\end{tabular}

Fontes: Szmrecsányi e Ramos, 2004.

Isto ajuda a entender porque a meta de 6 milhões de toneladas foi plenamente atingida em meados da década de 1970, como mostram os dados da Tabela 15. Nela também se pode ver como parte significativa da produção de álcool anidro era destinada ao consumo como álcool carburante, dando prosseguimento à antiga prática de mistura à gasolina, como visto na parte anterior deste trabalho.

Os preços internacionais do açúcar já estavam em queda no início de 1975, como há pouco mencionado. Os preços obtidos pelas exportações brasileiras, seja para o mercado preferencial norte-americano, seja para o mercado livre mundial acompanharam esse movimento e caíram muito até 1979, conforme pode ser visto nos dados da Tabela 13. Isto implicou uma retração nas quantidades exportadas. No seu relatório anual de 1980, o IAA reconheceu que "no último quadriênio (1976-79) (...) o açúcar de exportação apresentou preços altamente gravosos para a economia do setor $e$ conseqüentemente do País."

Esta retração se deu exatamente quando estava ocorrendo o aproveitamento da ampliação da capacidade de esmagamento de cana das fábricas, principalmente as de São Paulo, como indicam os dados das tabelas. E não se tratava apenas disso, mas também do fato de que os usineiros haviam 
ampliado seus canaviais e estimulado a ampliação dos canaviais de seus fornecedores. Assim, de um momento para o outro, os produtores viram-se diante de uma capacidade ociosa significativa.

Como se sabe, os usineiros brasileiros são grandes proprietários fundiários e em suas terras produzem a esmagadora maioria das canas que processam em suas fábricas (usinas e destilarias). Em São Paulo, o porcentual de “cana própria” moída era de 60\% em 1980/1981, conforme os dados do IAA. Contudo, é sabido que esse porcentual sempre foi, na realidade, muito maior, seja porque era comum o uso de práticas que dissimulavam os reais números, já que a lei não permitia um porcentual maior, seja porque muitos parentes de usineiros eram considerados fornecedores. Além disso, cabe lembrar que uma parte da cana colhida nas terras de fornecedores era produzida pelos próprios usineiros, por meio da prática de arrendamento.

Para sorte deles, havia ocorrido pouco antes disso, mais exatamente em outubro de 1973, o primeiro choque nos preços internacionais do petróleo. A este fato, portanto, veio associar-se a mencionada queda dos preços de exportação de açúcar, e ambos explicam o surgimento do Programa Nacional do Álcool (Proálcool) em novembro de 1975, cujo objetivo último sempre foi o de ampliar o mercado de álcool carburante, viabilizando a utilização e mesmo a continuidade da ampliação da capacidade de esmagamento de cana no Brasil.

Tabela 15 - Brasil - Evolução da produção de açúcar e de álcool e do consumo de álcool carburante entre 1966 e 1982

\begin{tabular}{|c|c|c|c|c|c|c|c|c|c|}
\hline \multirow{2}{*}{$\begin{array}{l}\text { Safra/Ano } \\
\left(^{*}\right)\end{array}$} & \multicolumn{3}{|c|}{ Produção de Açúcar } & \multicolumn{3}{|c|}{ Produção de Álcool } & \multicolumn{3}{|c|}{ Consumo de Álcool Carburante } \\
\hline & Em $1000 \mathrm{t}$. & \% S.P. & $\%$ Exp. & $\mathrm{Em} \mathrm{m}^{3}$ & \% S.P. & $\%$ Anidro & Anidro & Hidratado & \% Produção \\
\hline 1966 & $4.558,93$ & 55,4 & 22,3 & 602.707 & 66,7 & 55,8 & 365.922 & 0 & 60,7 \\
\hline 1967 & $4.115,92$ & 44,5 & 24,6 & 727.478 & 71,4 & 52,5 & 437.202 & 0 & 60,1 \\
\hline 1968 & $4.215,67$ & 44,5 & 26,0 & 676.262 & 73,4 & 53,0 & 191.300 & 0 & 28,3 \\
\hline 1969 & $4.111,83$ & 49,0 & 26,3 & 473.645 & 61,9 & 30,3 & 31.845 & 0 & 6,8 \\
\hline 1970 & $4.332,94$ & 43,6 & 26,5 & 461.609 & 58,1 & 21,8 & 183.606 & 0 & 39,8 \\
\hline 1971 & $5.119,66$ & 47,6 & 24,3 & 637.238 & 68,5 & 39,6 & 253.835 & 0 & 39,8 \\
\hline 1972 & $5.386,42$ & 48,2 & 48,9 & 613.068 & 73,9 & 63,6 & 391.143 & 0 & 63,8 \\
\hline 1973 & $5.932,46$ & 47,8 & 50,1 & 680.972 & 73,4 & 57,1 & 308.812 & 0 & 45,4 \\
\hline 1974 & $6.682,91$ & 52,5 & 34,2 & 665.979 & 68,3 & 46,0 & 190.170 & 0 & 28,6 \\
\hline 1975 & $6.720,58$ & 49,8 & 25,7 & 624.985 & 65,3 & 34,7 & 162.165 & 0 & 26,0 \\
\hline 1976 & $5.887,60$ & 48,7 & 21,0 & 555.627 & 65,2 & 41,9 & 171.572 & 0 & 30,9 \\
\hline 1977 & $7.208,21$ & 49,4 & 34,5 & 664.022 & 69,8 & 45,2 & 639.299 & 0 & 96,3 \\
\hline 1978 & $8.307,61$ & 49,3 & 23,2 & 1.470 .404 & 74,5 & 80,0 & 1.505 .735 & 0 & 102,4 \\
\hline 1979 & $7.342,42$ & 43,5 & 26,4 & 2.490 .603 & 72,8 & 84,1 & 2.271 .127 & 301.979 & 103,3 \\
\hline 1980 & $6.646,23$ & 41,5 & 38,7 & 3.396 .455 & 72,8 & 79,9 & 2.253 .108 & 403.190 & 78,2 \\
\hline 1981 & $8.100,30$ & 47,4 & 31,9 & 3.706 .375 & 70,4 & 56,8 & 1.146 .015 & 1.811 .271 & 79,8 \\
\hline 1982 & $7.935,32$ & 49,3 & 33,6 & 4.240 .123 & 66,8 & 34,3 & 2.020 .908 & 1.717 .720 & 88,2 \\
\hline
\end{tabular}

Fonte: I.A.A.

Nota: (*) As produções referem-se às safras (1965/1966, etc.); a exportação de açúcar e o consumo de álcool referem-se aos anos civis (1966, etc.). 
Elaborado e anunciado de maneira relativamente apressada, atendendo, portanto, aos interesses mais imediatos dos produtores de açúcar e de álcool e de equipamentos e acessórios afins, os quais também haviam ampliado sua capacidade de oferta, o programa careceu do efetivo apoio e envolvimento de outros agentes relacionados ao mercado de combustíveis no Brasil, o que explica sua reformulação em 1977. Estes fatos explicam porque, num primeiro momento, ocorreu uma significativa elevação da produção e consumo de álcool anidro carburante, o que os dados da Tabela 15 revelam. Com a ocorrência do segundo choque dos preços do petróleo, em janeiro de 1979, reforçou-se a justificativa do programa, tornando vitoriosa a posição dos que defendiam que o apoio e estímulo à produção e ao consumo de álcool contemplassem também o hidratado, para ser usado como combustível isolado em automóveis movidos a álcool. Assim, a partir daquele ano, as montadoras multinacionais instaladas no Brasil aderiram ao programa e começaram a produzir tais veículos no País. Os seguintes dados ilustram o ocorrido: as vendas de veículos movidos á álcool foram de 3,1 mil unidades em 1979; de 240,7 mil em 1980; de 137,3 mil em 1981, e de 233,8 mil em 1982. Além disso, foram convertidos a álcool veículos antes movidos à gasolina: em 1979, 5.021 unidades; em 1980, 29.015 unidades, e em 1981, 16.093 unidades.

Tabela 16 - Distribuição das aplicações do plano de racionalização (1977) e dos projetos aprovados pelo Proálcool - 1981 (capacidade de produção em milhões de litros/safra)

\begin{tabular}{|c|c|c|c|c|c|c|c|c|c|}
\hline \multicolumn{4}{|c|}{ Aplicações do FEE (até 31/12/1977) } & \multicolumn{6}{|c|}{ Projetos aprovados pelo Proálcool (até 31/12/81) } \\
\hline Estado & $\%$ & Atividade & $\%$ & \multirow{2}{*}{ Estado } & \multicolumn{2}{|c|}{ Destilarias } & \multicolumn{2}{|c|}{$\begin{array}{l}\text { Destilarias } \\
\text { Autônomas }\end{array}$} & \multirow{2}{*}{$\begin{array}{c}\% \text { do } \\
\text { Total C. P } \\
\text { Destilarias }\end{array}$} \\
\hline S. Paulo & 28,7 & Modernização de usinas & 30,8 & & Núm. & C. P. $\left({ }^{* *}\right)$ & Núm. & C. P. $\left({ }^{* *}\right)$ & \\
\hline $\begin{array}{l}\text { Pernam- } \\
\text { buco }\end{array}$ & 23,2 & $\begin{array}{l}\text { Fusão, relocalização e } \\
\text { incorporação de usinas }\end{array}$ & 15,5 & São Paulo & 84 & $-1.769,2$ & -67 & $-1.242,9$ & 37,7 \\
\hline Alagoas & 23,0 & $\begin{array}{l}\text { Equalização e subsídio de preço } \\
\text { ao consumidor }\end{array}$ & 31,3 & $\begin{array}{l}\text { Pernam- } \\
\text { buco }\end{array}$ & 23 & 274,1 & 06 & 90,0 & 4,6 \\
\hline $\begin{array}{l}\text { Rio de } \\
\text { Janeiro }\end{array}$ & 9,0 & $\begin{array}{l}\text { Reforço de capital de giro às } \\
\text { coops. produtores de açúcar }\end{array}$ & 10,0 & Alagoas & 25 & 457,4 & 10 & 289,4 & 9,3 \\
\hline Subtotal & 83,9 & $\begin{array}{l}\text { Reforço de capital de giro às } \\
\text { cooperativas de fornecedores }\end{array}$ & 3,9 & $\begin{array}{l}\text { Rio de } \\
\text { Janeiro }\end{array}$ & 12 & 162,4 & 01 & 27,0 & 2,4 \\
\hline Demais & 16,1 & Demais atividades $\left({ }^{*}\right)$ & 8,4 & Demais & 31 & 465,7 & 134 & $3.209,8$ & 46,0 \\
\hline BRASIL & 100 & Total & 100 & BRASIL & 175 & $3.128,8$ & 218 & $4.859,1$ & 100,0 \\
\hline
\end{tabular}

Fontes: Szmrecsányi e Ramos, 2004.

Notas: (*) Referem-se a: incorporação de cotas de fornecedores, subsídios de juros nos financiamentos de entressafra e de expansão de lavouras, financiamento de máquinas e implementos às cooperativas de fornecedores de cana, reforço de infra-estrutura de exportação e Programa Nacional de Melhoramento de Cana-de-Açúcar; $\left({ }^{*}\right.$ ) C.P.= Capacidade de Produção prevista nos projetos de destilarias aprovados.

A Tabela 16 traz dados referentes à distribuição da aplicação dos recursos do FEE (Plano de Racionalização) e do Proálcool. Convém destacar a participação de São Paulo nos dois planos e dos recursos destinados à modernização e fusão, relocalização e incorporação de usinas nas aplicações do FEE. No caso dos recursos do Proálcool, chama a atenção a participação das destilarias autônomas montadas para a fabricação principalmente de álcool hidratado. Assim, ocorreu não apenas a instalação ou ampliação de destilarias anexas, mas o surgimento de novas fábricas, de propriedade tanto dos tradicionais produtores como de novos, instaladas em áreas que antes eram utilizadas pela pecuária extensiva, principalmente na região Centro/Sul do Brasil. 
Finalmente, cabe destacar que os subsídios embutidos nos financiamentos de tais programas, segundo estimativas disponíveis, alcançaram, entre 1975 e 1989, um valor médio anual de US\$ 500 milhões, beneficiando tanto antigos como novos produtores da agroindústria canavieira do Brasil. Este cálculo não leva em conta outros programas, tal como o do crédito rural, cujos dados mostram que a lavoura de cana tem sido uma das mais contempladas, já que é comum ocorrer perdão parcial de dívidas. (mais detalhes estão no trabalho de Szmrecsányi e Ramos, 2004).

\section{OBSERVAÇÕES FINAIS}

O que se demonstrou foi que a produção mundial de açúcar expandiu-se muito entre 1930 e 1960, em grande medida como resultado das políticas implementadas pelos países desenvolvidos, seja aproveitando recursos em seus próprios territórios, seja com base em arranjos bilaterais com países que foram colônias ou que estavam sob suas influências, estabelecendo-se práticas que em nada lembram o liberalismo econômico tão propalado em nossos dias. Tais políticas açucareiras sempre foram protecionistas, de defesa de mercados e dos capitais investidos na produção de açúcar, estivessem eles atuando ou não em seus territórios. Embora alguns insistam no fato de que o açúcar de beterraba apresenta um custo maior que o da cana, não foi isto que serviu de parâmetro para a circulação mundial deste produto. Com a grande maioria do açúcar (de cana ou de beterraba) circulando pelo mundo sob a instituição dos mercados preferenciais, os acordos mundiais fracassaram em seus objetivos de estabilizar os preços ou de evitar a formação e expansão dos excedentes.

Quanto à situação do Brasil, mostrou-se que o mercado de açúcar fez parte da expansão e consolidação de seu mercado interno, tendo se confundido com o processo mais amplo de industrialização/urbanização da economia brasileira que se destacou a partir da segunda metade do século XIX, mas principalmente após 1930, quando ocorreu o que Celso Furtado denominou de "deslocamento do centro dinâmico" da economia brasileira. (Furtado, 1977, cap. XXXII). Tratouse, portanto, de uma expansão fundamentalmente endógena viabilizada pela orientação "nacional/ desenvolvimentista" que marcou a economia e a ação do Estado após a crise de 1929. Fez parte deste processo a concentração socioeconômica em São Paulo, mas cuja exportação de açúcar somente passou a ser expressiva no final da década de 1950.

Assim, a devida compreensão da história da agroindústria canavieira do Brasil, no período tratado, ocorre quando o açúcar não é tido como bem de exportação e tampouco agrícola. O Brasil somente voltou a ser um exportador importante depois de ter se tornado um grande produtor para o mercado interno. Finalmente, demonstrou-se o elo entre o mercado de açúcar e o de álcool, especialmente o de uso carburante, ficando explicitado que tal uso não surgiu em 1975, como podem pensar os que desconhecem aquela história.

\section{REFERÊNCIAS BIBLIOGRÁFICAS}

ALBUQUERQUE, M. C. C; NICOL, R. Economia agrícola - o setor primário e a evolução da economia brasileira. São Paulo: Ed. McGraw-Hill, 1987.

BARROS, B. C. Cana-de-açúcar. Revista de Economia Rural, SOBER, Rio de Janeiro, v. I, n. 1, p. 469-480 e 487-490, jun. 1968. 
BRIEGER, F. O. Elementos sobre agricultura e organização da política e economia da indústria açucareira. Brasil Açucareiro, p. 50-55, jun. 1967.

CARNEIRO, W. Açúcar demerara, matéria-prima da refinação. Brasil Açucareiro, p. 62-73, dez. 1970, CABRAL, T. O açúcar no mundo. Anuário Açucareiro 1936. Rio de Janeiro: IAA, p. 230-258.

DALTON, J. E.. Sugar - a case study of government control. New York: The Macmillan Company, 1937.

DÉ CARLI, G. Conferência internacional do açúcar. Brasil Açucareiro, p. 39-94, set. 1953.

FAO (Dirección de Productos Básicos y Comercio). Azúcar: Cuestiones importantes de comercio y estabilización en los años 80. Roma, 1985.

FURTADO, Celso. Formação econômica do Brasil. São Paulo: Ed. Nacional, $15^{\mathrm{a}}$ ed., 1977.

IAA (Inst. do Açúcar e do Álcool). Brasil/Açúcar. Rio de Janeiro, 1972. (Coleção Canavieira n. 8). . Informações sobre açúcar e álcool. Brasil Açucareiro, pp. 9-16, out. 1976.

INTERNACIONAL SUGAR COUNCIL. The world sugar economy structure and policies. Londres: Conselho Internacional do Açúcar, 1963. (v. I, National Sugar Economies and Policies).

JANK, M. S. A revolução tecnológica e o papel da CEE no mercado internacional de açúcar. Revista Brasileira de Comércio Exterior, n. 22, ano IV, p. 30-34, março-abril 1989.

JOHNSTON, B. F.; KILBY, P. Agricultura e transformação estrutural. Rio de Janeiro: Zahar Eds., 1977.

LIPPMANN, E. O. von. História do açúcar. Rio de Janeiro: IAA, 1940-1942. 2 v.

LÓPEZ, F. C.. La Industria azucarera en Cuba. La Habana, Ed. de Ciencias Sociales, 1982.

Mont'Alegre, O. Política internacional do açúcar. Brasil Açucareiro, p. 98-106, set. 1955.

. Política internacional do açúcar. Brasil Açucareiro, p. 81-91, out. 1955.

. A Conferência do açúcar - Genebra, 1958. Brasil Açucareiro, p. 26-37, dez. 1958.

. Açúcar, economia caprichosa. Brasil Açucareiro, p. 8-13, out. 1964.

. A economia açucareira mundial nos anos 60. Brasil Açucareiro, p. 59-89, jul. 1971.

. Açúcar às vésperas de um novo acordo. Brasil Açucareiro, p. 20-42, jun. 1973.

. O colóquio do açúcar em Londres, Brasil Açucareiro, p. 29-41, maio/1975.

. Açúcar, antes e depois de mil dólares. Brasil Açucareiro, p. 46-72, jun. 1976.

Estrutura dos mercados de produtos primários. Rio de Janeiro: IAA, 1976-1977.

PLANALSUCAR. Superintendência Geral. Informes econômicos e estatísticos. Piracicaba, jul. 1979.

RAMOS, P. Um estudo da evolução e da estrutura da agroindústria canavieira do Estado de São Paulo (19301982). Dissertação (Mestrado) - EAESP-FGV, 1983.

. Agroindústria canavieira e propriedade fundiária no Brasil. São Paulo: Ed. Hucitec, 1999.

. O mercado mundial de açúcar no período 1930-1960. Revista de Política Agrícola (Secretaria

de Política Agrícola/Mapa), Brasília, ano X, n. 4, p. 26-33, out.-nov.-dez. 2001.

SZMRECSÁNYI, T. O planejamento da agroindústria canavieira do Brasil (1930-1975). São Paulo: Ed. Hucitec/Univ. Estadual de Campinas, 1979.

. Concorrência e complementaridade no setor açucareiro. Caderno de Difusão de Tecnologia, Brasília, 69 (2/3), p. 165-182, maio-dez. 1989.

.; MOREIRA, E. P. O desenvolvimento da agroindústria canavieira do Brasil desde a Segunda

Guerra Mundial. Estudos Avançados, São Paulo, v. 11, n. 5, 1991.

.; RAMOS, P. Agroindústria canavieira e política econômica no Século XX. In: CONFE-

RENCIA INTERNACIONAL NOVAS PERSPECTIVAS SOBRE HISTÓRIA ECONÔMICA

DO BRASIL. Araraquara: UNESP, Campus de Araraquara, set. 2004.

TRUDA, L. A defesa da produção açucareira. Rio de Janeiro: IAA, 1971. 
WATSON, F. Mercados interno e externo de açúcar. Brasil Açucareiro, p. 102-105, maio 1972. . O mercado interno e externo do açúcar. Brasil Açucareiro, p. 10-16, set. 1973.

WILLCOX, O. W. A economia dirigida na indústria açucareira. Rio de Janeiro: IAA, 1941. 